\title{
A review on available energy saving strategies for heating, ventilation and air conditioning in underground metro stations
}

Yanzhe Yu', Shijun You', ${ }^{1,2}$ Huan Zhang1,2, Tianzhen Ye ${ }^{1,2}$, Yaran Wang1,*, Shen Wei $^{3}$

1 = School of Environmental Science and Engineering, Tianjin University, Tianjin 300350, China

2 = National Engineering Laboratory for Digital Construction and Evaluation Technology of Urban Rail Transit, Tianjin 300072, China

$3=$ The Bartlett School of Construction and Project Management, University College London (UCL), 1-19 Torrington Place, London WC1E 7HB, United Kingdom

* Corresponding author. Email address: yaran_wang@tju.edu.cn (Y. Wang).

Email addresses:

yuyanzhe@tju.edu.cn (Y.Yu), yousj@tju.edu.cn (S.You), zhhuan@tju.edu.cn (H. Zhang), tzhye@tju.edu.cn (T. Ye), yaran_wang@tju.edu.cn (Y. Wang) and shen.wei@ucl.ac.uk (S. Wei). 


\begin{abstract}
Due to the increasing number of underground metro stations worldwide and the great energy consumption of heating, ventilation and air conditioning (HVAC) systems in underground stations, reducing the HVAC energy consumption while maintaining a hygienic and acceptable environment in underground stations is becoming an ongoing research challenge. This paper presented an overview of the strategies available for HVAC energy saving in underground stations. Firstly, the design features of the HVAC systems are summarized and issues affecting the HVAC systems' energy efficiency are identified. Then, a thorough review of the energy-efficient HVAC strategies is presented. For each strategy, the principal application and the effect on energy saving are described, and the limitation is also analyzed. Lastly, the strategies are classified and compared from different perspectives and upcoming challenges are proposed. The authors hope that this study can promote the reasonable adoption of different energy-efficient HVAC strategies in underground stations, which could reduce the energy consumption of the HVAC systems in the long run.
\end{abstract}

\title{
Highlights
}

Design features of the HVAC system in underground stations are summarized.

Issues affecting HVAC systems' energy efficiency in existing stations are identified.

Various strategies for HVAC energy saving in underground stations are reviewed.

The novel HVAC strategies are classified and compared from different perspectives.

Applicability and upcoming challenges of the HVAC strategies are discussed.

\section{Keywords}

Energy-saving, underground stations, ventilation, air-conditioning, strategies

\section{Word count}

7527 words (excluding title, author names and affiliations, keywords, abbreviations, table/figure captions, acknowledgments and references) 


\begin{tabular}{|c|c|c|c|}
\hline \multicolumn{4}{|c|}{ Abbreviations } \\
\hline UMSs & Underground Metro Stations & DX A/C & Direct expansion Air-Conditioning \\
\hline HVAC & $\begin{array}{l}\text { Heating, Ventilation, and Air } \\
\text { Conditioning }\end{array}$ & ICAE & $\begin{array}{l}\text { International Conference on } \\
\text { Applied Energy }\end{array}$ \\
\hline ISHVAC & $\begin{array}{l}\text { International Symposium on } \\
\text { Heating, Ventilation and Air } \\
\text { Conditioning }\end{array}$ & ASHRAE & $\begin{array}{l}\text { American Society of Heating, } \\
\text { Refrigerating and Air-Conditioning } \\
\text { Engineers }\end{array}$ \\
\hline IAQ & Indoor Air Quality & ASHPs & Air Source Heat Pumps \\
\hline RWI & Relative Warmth Index & GSHPs & Ground Source Heat Pumps \\
\hline $\mathrm{CO}_{2}$ & Carbon Dioxide & WSHPs & Water Source Heat Pumps \\
\hline PM & Particulate Matter & SES & Subway Environment Simulation \\
\hline UPE & Under Platform Exhaust & IDA & IDA tunnel simulation software \\
\hline PSDs & Platform Screen Doors & PID & Proportional Integral Derivative \\
\hline APGs & Automatic Platform Gates & MPC & Model Predictive Control \\
\hline PBDs & Platform Bailout Doors & TRNSYS & Transient System Simulation Tool \\
\hline AVPDs & $\begin{array}{l}\text { Adjustable Ventilation } \\
\text { Platform Doors }\end{array}$ & STESS & $\begin{array}{l}\text { Subway Thermal Environment } \\
\text { Simulation Software }\end{array}$ \\
\hline $\mathrm{CoP}$ & Coefficient of Performance & CFD & Computational Fluid Dynamics \\
\hline VFDs & Variable Frequency Devices & & \\
\hline
\end{tabular}




\section{Introduction}

By the end of 2017, metros were available in 178 cities of 56 countries, responsible for delivering around a total of 168 million passengers per day [1]. Comparing with other over-ground transportations, such as buses and trams, metros can efficiently use underground space to share the high burden of transportation in major cities $[2,3]$. Underground metro stations (UMSs) are the basic entrance of occupants to the metro services and they are a special kind of buildings built beneath the ground. Because these stations are built under the ground, their indoor environment and energy efficiency are more difficult to maintain than traditional buildings [4-6].

To provide metro passengers with a healthy, comfortable and safe environment, heating, ventilation and air conditioning (HVAC) systems are available in almost every UMS used for regulating indoor environmental parameters, such as air temperature, humidity, air speed and particle concentrations $[7,8]$. However, when doing this work, they are consuming high-level energy as well [9-11]. In 2015, the energy consumption from the HVAC systems available in all metro stations in Beijing, China, was approximately 490 GWh, which can power nearly 255,500 families for a year [12]. In Barcelona, Spain, 84.2 MWh/year was used in one of their oldest underground stations for ventilation only [13]. Comparison between continents also revealed that the energy demand by HVAC systems may be geography dependent, as Asia requires more energy than Europe, North America and Latin American [14,15].

Due to the high demand of HVAC energy in UMSs, it is essential to develop energy efficient strategies for them. Zhang et al. [16] have investigated the energy performance of an innovative environmental control system in a UMS and identified an energy saving potential of $20.6-60.4 \%$ under different situations. Yang et al. [17] have tried to use frequency conversion technology for the operation of pumps and fans in UMSs and suggested a total power saving ratio ranging between $59.5-73.4 \%$. Besides these, there were also some other studies that have identified an energy saving potential over $30 \%$ when applying energy efficient solutions to existing systems [18-20]. 
Despite various studies have been proved the energy saving potential of the HVAC systems by conducting on one specific technology or individual solution (such as platform screen door systems, variable frequency devices, direct expansion airconditioning, artificial intelligent ventilation, etc.) while maintaining an acceptable environment, but a comprehensive study that summarizes a wide range of different strategies and technologies for HVAC energy savings is still lacking. Furthermore, the energy demand and performance of the HVAC systems in UMSs are influenced by different influential factors. Finding the most suitable energy saving strategy that can properly handle various factors and achieve the overall optimization of the entire HVAC system in UMSs is an ongoing challenge for current research community.

Therefore, the objectives of this review are (i) to summarize the design features of the existing HVAC systems used in UMSs to help researchers/designers identify the most relevant variables of the station environment and major issues that can affect the system's energy efficiency; (ii) to investigate the characteristics and compare the performances of different energy saving HVAC strategies; and (iii) to analyze the applicability and upcoming challenges of the energy saving HVAC strategies for achieving low-energy underground stations.

\section{Materials and methods}

The research methodology was composed of three primary steps:

First, a keyword-based search of research articles was conducted using major international online databases, such as Web of Science and Scopus. Examples of the keywords used were listed in Table 1. Based on the research theme, the keywords were divided into three categories (site, HVAC strategy, and energy) and the keywords belonging to each category were cross-used in the literature search. 
of their operational mechanisms and energy saving potential, and discusses the direction of future improvements. A thorough conclusion of the paper is provided in Section 6 .

\section{Design features of HVAC systems in UMSs}

Because UMSs are built under the ground, they have special requirements that need to be considered when designing and operating their HVAC systems. An in-depth understanding of these requirements/design features is important for developing energy efficient solutions. This section, therefore, has described these requirements by answering the following three questions:

1. What are the environmental requirements (design conditions) in UMSs (Section 3.1)?

2. What are the major influential factors on stations' indoor environment (Section 3.2)?

3. What HVAC systems are available for UMSs (Section 3.3)?

\subsection{Environmental criteria in UMSs}

\subsubsection{Thermal comfort inside metro stations}

Environmental requirements in UMSs can be mainly divided into thermal comfort and indoor air quality (IAQ). According to standard ASHRAE 55 [21], thermal comfort is 'that condition of mind which expresses satisfaction with the thermal environment'. Thermal environment represents the characteristics of the environment, which affect the heat exchange between the human body and the environment. Currently, it is widely acknowledged that people's thermal comfort/sensation is affected by four environmental parameters, namely, air temperature, mean radiant temperature, relative humidity and air velocity, and two personal parameters, namely, metabolic rate and clothing insulation, defined by Fanger's predicted mean vote model [22], which has been adopted in many major building design standards, such as ISO 7730 [23], EN 15251 [24] and ASHRAE 55. Among these parameters, mean radiant temperature is defined as 'the uniform temperature of an imaginary enclosure in which radiant heat transfer from the human body is equal to the radiant heat transfer in the actual nonuniform enclosure'; the metabolic rate is defined as 'a conversion of chemical into 
mechanical and thermal energy, measures the energetic cost of muscular load and gives a numerical index of activity (such as it is $54 \mathrm{Btu} / \mathrm{h} . \mathrm{ft}^{2}$ at the entrance and $39 \mathrm{Btu} / \mathrm{h} . \mathrm{ft}^{2}$ at the platform in UMSs)'. For the remaining parameters, please also refer to [22].

In UMSs, indoor air temperature and relative humidity are the two main parameters used to control the indoor thermal environment [25,26]. For example, according to [27], in China, it is recommended to maintain indoor temperature $\leqslant 30^{\circ} \mathrm{C}$ for station halls and $\leqslant 29^{\circ} \mathrm{C}$ for platforms, with relative humidity between $40 \%$ and $70 \%$ for both of them, in summer. In winter, the temperature should be maintained $\geqslant 12^{\circ} \mathrm{C}$ for both of them, but without any specific requirement on humidity.

For UMSs, there is another index called relative warmth index (RWI) [28] that is commonly used in studies to evaluate indoor thermal comfort level. The RWI is developed by ASHRAE, and can be used to determine how warm a person feels in UMSs. It is a dimensionless parameter, considering parameters like temperature, air velocity, clothing insulation and metabolic rate. This parameter has considered the impact of transient effect on occupants' thermal sensation in the station design, which often gives a higher design temperature $\left(3-5^{\circ} \mathrm{C}\right)$ in summer than that decided by the steady-state method, resulting in reduced cooling load of air-conditioning systems [28]. According to [25], RWI can be calculated by Equations 1 and 2 for different ambient vapor pressure conditions.

$$
\begin{aligned}
& R W I=\frac{M\left(I_{c w}+I_{a}\right)+1.13(t-95)+R I_{a}}{70(1.73-P)}(P>0.67 \text { in } \mathrm{Hg}) \\
& R W I=\frac{M\left(I_{c w}+I_{a}\right)+1.13(t-95)+R I_{a}}{74.2}(P \leq 0.67 \text { in } \mathrm{Hg})
\end{aligned}
$$

where $M$ is metabolic rate $\left(\mathrm{Btu} / \mathrm{h} . \mathrm{ft}^{2}\right) ; I_{c w}$ is wet clothing insulation (clo); $I_{a}$ is air boundary insulation (clo); $t$ is dry bulb temperature $(\mathrm{F}) ; R$ is mean incident radiant heat from sources other than walls at room temperature $\left(\mathrm{Btu} / \mathrm{h} . \mathrm{ft}^{2}\right)$, and $P$ is vapor pressure of water in air (inch of mercury, in $\mathrm{Hg}$ ). 
Table 2 relates RWI and the ASHRAE comfort classification, the acceptable range of RWI values is between 0 and 0.15 [25].

\section{Table 2}

ASHRAE comfort classification using RWI [25].

\begin{tabular}{cl}
\hline ASHRAE comfort classification & RWI \\
\hline Warm & 0.25 \\
Slightly warm & 0.15 \\
Comfortable & 0.08 \\
Slightly cool & 0.00 \\
\hline
\end{tabular}

ISO 7726 [29] has given a detailed technical description about the measurement of these thermal factors used to evaluate indoor thermal environment, including air temperature, mean radiant temperature, relative humidity and air velocity. According to the standard, air temperature should be measured by a thermocouple or a thermistor, at a height of abdomen level for homogeneous environment or at heights of head level, abdomen level and ankle level for heterogeneous environment. Mean radiant temperature should be measured by a black globe thermometer, only at the height of abdomen level. Humidity should be measured by a psychrometer or a whirling hygrometer, only at the height of abdomen level. Air velocity should be measured by a hot-wire/sphere anemometer, at the same height(s) as temperature. For metabolic rate and clothing insulation, ISO 7730 [23] has given useful checklists based on people's activities (to decide metabolic rate) and combination of garments (to decide clothing insulation). In UMSs, temperature and humidity sensors are commonly installed to reflect the thermal environment of the station [24], with other parameters, such as air velocity [30,31] and mean radiant temperature $[32,33]$, were also measured in some research studies.

\subsubsection{IAQ inside metro stations}

According to CIBSE KS17 [34], IAQ is 'the air quality within and around buildings and structures, especially as it relates to the health and comfort of building occupants, and good IAQ can be defined as air with no known contaminants at harmful concentrations'. Common indoor contaminants or pollutants include carbon dioxide 
$\left(\mathrm{CO}_{2}\right)$, volatile organic compounds, odors and particulates. In UMSs, indoor $\mathrm{CO}_{2}$ [35] and particulate matters (PMs) concentration $[5,36]$ are major environmental parameters linked with IAQ:

$\mathrm{CO}_{2}$ concentration: a widely used parameter to decide ventilation rate in buildings (i.e. the demand control ventilation), including metro stations, because of its good reflection of occupancy levels indoors [37]. The limit of $\mathrm{CO}_{2}$ concentration in metro stations may be different between countries, such as 1000 ppm in Korea and 1500 ppm in China [38].

PM concentration: another important parameter used to control IAQ, mainly focusing on $\mathrm{PM}_{2.5}$ and $\mathrm{PM}_{10}$ concentrations. In metro stations, these particles come from 1) mechanical wear and friction processes between rails and wheels or between pantographs and trains; 2) erosion of construction materials, and 3) particles brought from outdoors by piston wind [4,5]. Because $\mathrm{PM}_{2.5}$ is included in $\mathrm{PM}_{10}$, the official limitation set for $\mathrm{PM}_{10}$ is always higher than that for $\mathrm{PM}_{2.5}$. For example, for UMSs in Korea, the upper limitation for $\mathrm{PM}_{2.5}$ is set as $40 \mu \mathrm{g} / \mathrm{m}^{3}$ and for $\mathrm{PM}_{10}$ the value is 150 $\mu \mathrm{g} / \mathrm{m}^{3}[39]$.

\subsection{Influential factors of stations' indoor environment}

When designing UMSs, the most challenging part is for their public areas (halls and platforms), due to their high population and complex internal environment [28]. Figure 1 has shown possible factors that may influence the indoor thermal environment of UMSs, with heat gains for public areas coming from 1) outdoor air; 2) tunnel air; 3) passengers; 4) station devices; 5) mechanical fresh air, and 6) earth. Little effect is coming from external solar radiation, but strong dependencies exist to piston effect and heat sink effect [25]. The piston effect enables stations exchange heat with both outdoor environment and tunnel environment, and the heat sink effect has an influence on the heat exchange between stations/tunnels and earth. Due to this complexity, most studies in UMSs focused on developing energy efficient strategies for public areas. 


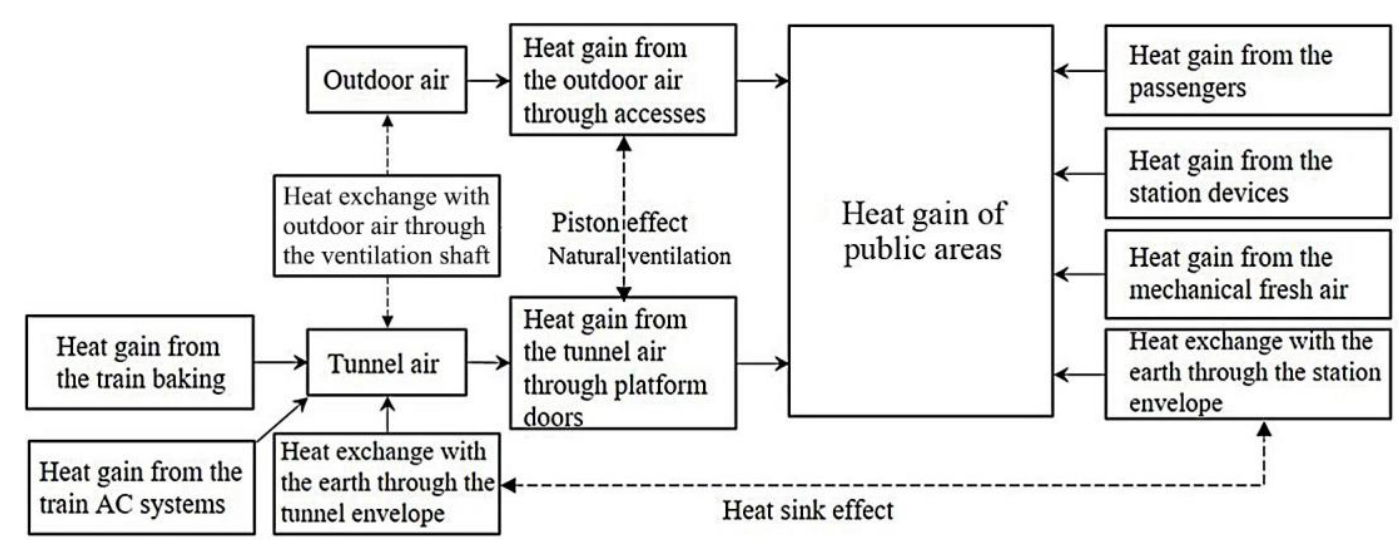

Figure 1: Schematic of heat gains for the public areas of typical underground stations.

In terms of IAQ, the influences are mainly determined by pollutant sources and propagation (including driving force and the route). In UMSs, the main source of $\mathrm{CO}_{2}$ is metro passengers, but for PMs, their sources are more complicated, as mentioned in Section 3.1 and shown in Figure 2. The propagation of pollutants is mainly driven by piston wind, and natural ventilation when there is no mechanical ventilation. It is also affected by the layout of stations, such as the number and length of accesses, the volume of public areas, the form of platform doors, and the location of ventilation shafts, etc.

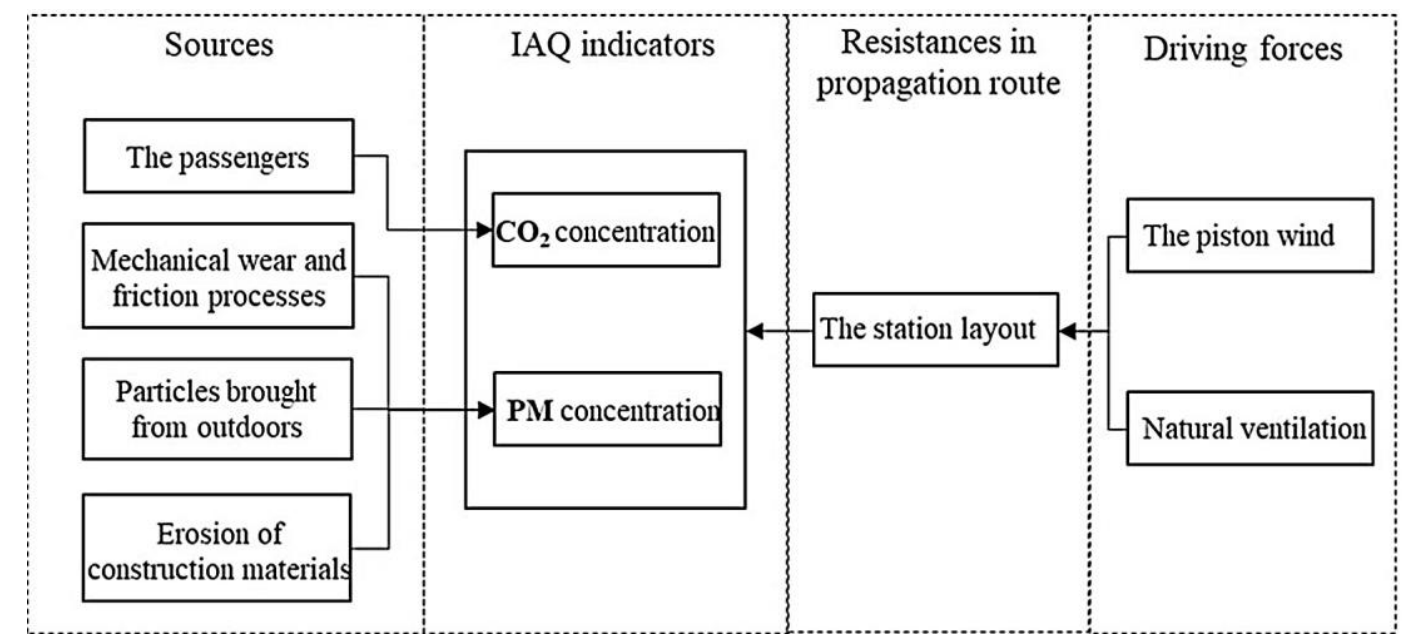

Figure 2: Schematic of IAQ influential factors for the public area.

\subsection{HVAC systems in UMSs}

Due to the complexity of the environment of UMSs, various systems have been developed to suit different function requirements. These systems can generally be classified into 1) public areas HVAC system [40,41], 2) under platform exhaust (UPE) 
system [42], and 3) tunnel ventilation system [43,44].

Public areas HVAC systems: with main functions to 1) control the indoor environment; 2) ensure enough fresh air; and 3) remove smoke in case of a fire. The primary air return system, as shown in Figure 3, is a common form used in the station where cooling is needed [45], such as in most countries in Asia [14,15]. In Europe, the major system form is mechanical ventilation systems equipped with variable frequency drives to regulate the fan speed under various environmental conditions [13]. When using these systems in UMSs, there are some major issues that can affect the system's energy efficiency: 1) the impact from train-induced airflow on HVAC load $[13,40]$; 2) a high proportion of energy consumption on moving mediums, including both air and water, in the system due to the large volume of stations [46]; 3) potential influential factors, such as outdoor environment and occupancy level, affecting the system performance $[18]$.

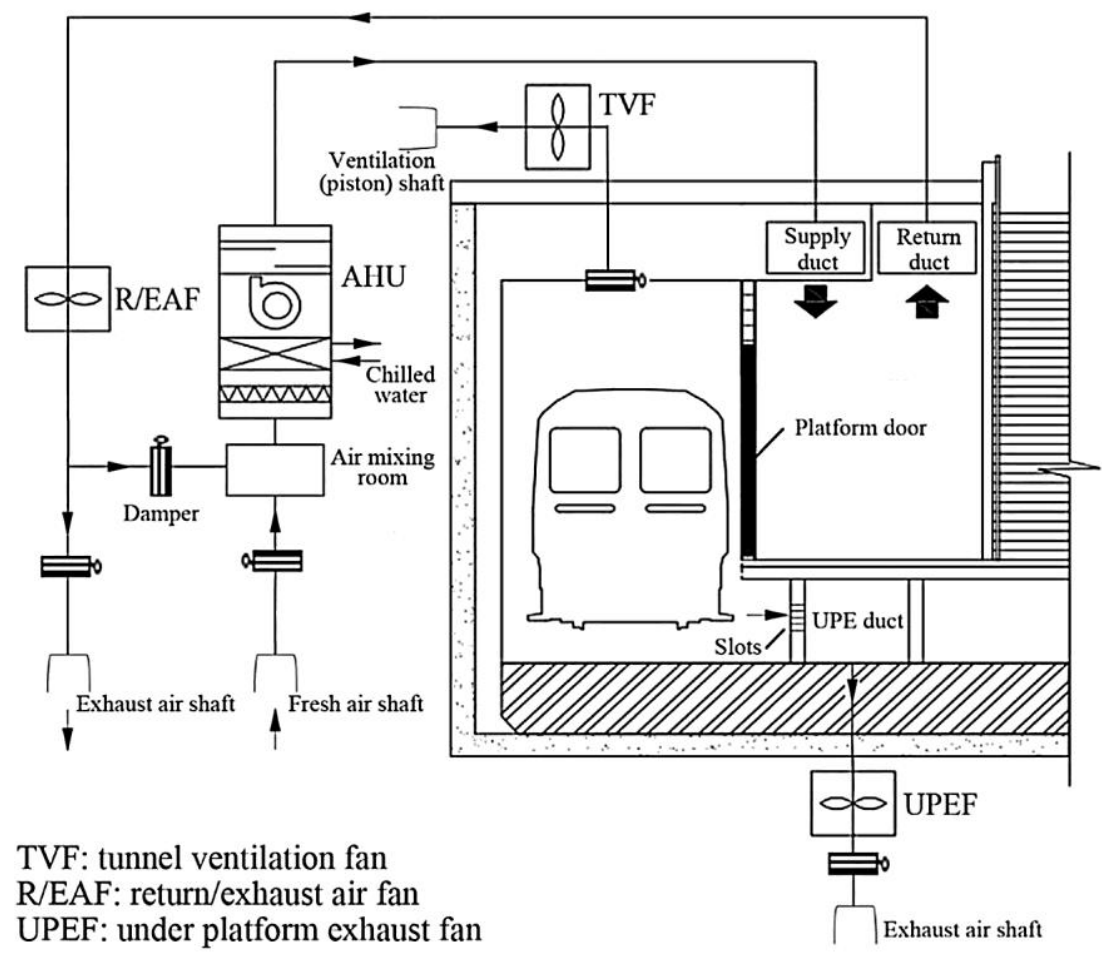

Figure 3: Schematic of a typical HVAC system in UMSs.

Under platform exhaust (UPE) systems: with a main function to remove heat generated from train braking before it enters the platform [47]. The UPE duct is 
installed beneath the platform, with many slots on it to capture heat, as shown in Figure 3 as well. It links to exhaust air shafts at both sides, exhausting hot air from tunnels to outdoors, driven by UPE fans. When using this system in UMSs, there are some major issues that can affect the system's energy efficiency: 1) high energy demand from fans $[42,47] ; 2)$ extracting conditioned air from the platform, leading to energy waste [48].

Tunnel ventilation systems: with main functions to 1) keep an acceptable environment in tunnels under normal circumstances; 2) control air and smoke movement in emergency, such as a fire, happening in tunnels [49]. This system usually includes tunnel ventilation fans, ventilation (piston) shafts and dampers installed on the tunnel, as indicated in Figure 3. Besides ventilation, the ventilation shaft can also attenuate possible pressure fluctuations originating from the piston effect when the fan is off [49]. When using this system in UMSs, there is one major factor that can affect the system's energy efficiency: the design of ventilation shafts on ventilation efficiency, for example, changing the location or the cross-sectional area of shafts would affect the air exchanging rate between tunnels and outdoors, which indirectly influence the energy consumption of ventilation systems $[49,50]$.

\section{Overview of the energy saving HVAC strategies for UMSs}

Figure 4 has listed the available strategies that can help to achieve higher energy efficiency of HVAC systems in UMSs, grouped for the three systems classified in Section 3.3. Apparently, as mentioned previously, most attentions have been put into the public areas of UMSs, with eight available solutions. According to the review results in this study, only one kind of solution has been proposed for each of UPE systems and tunnel ventilation systems to improve their performance. 


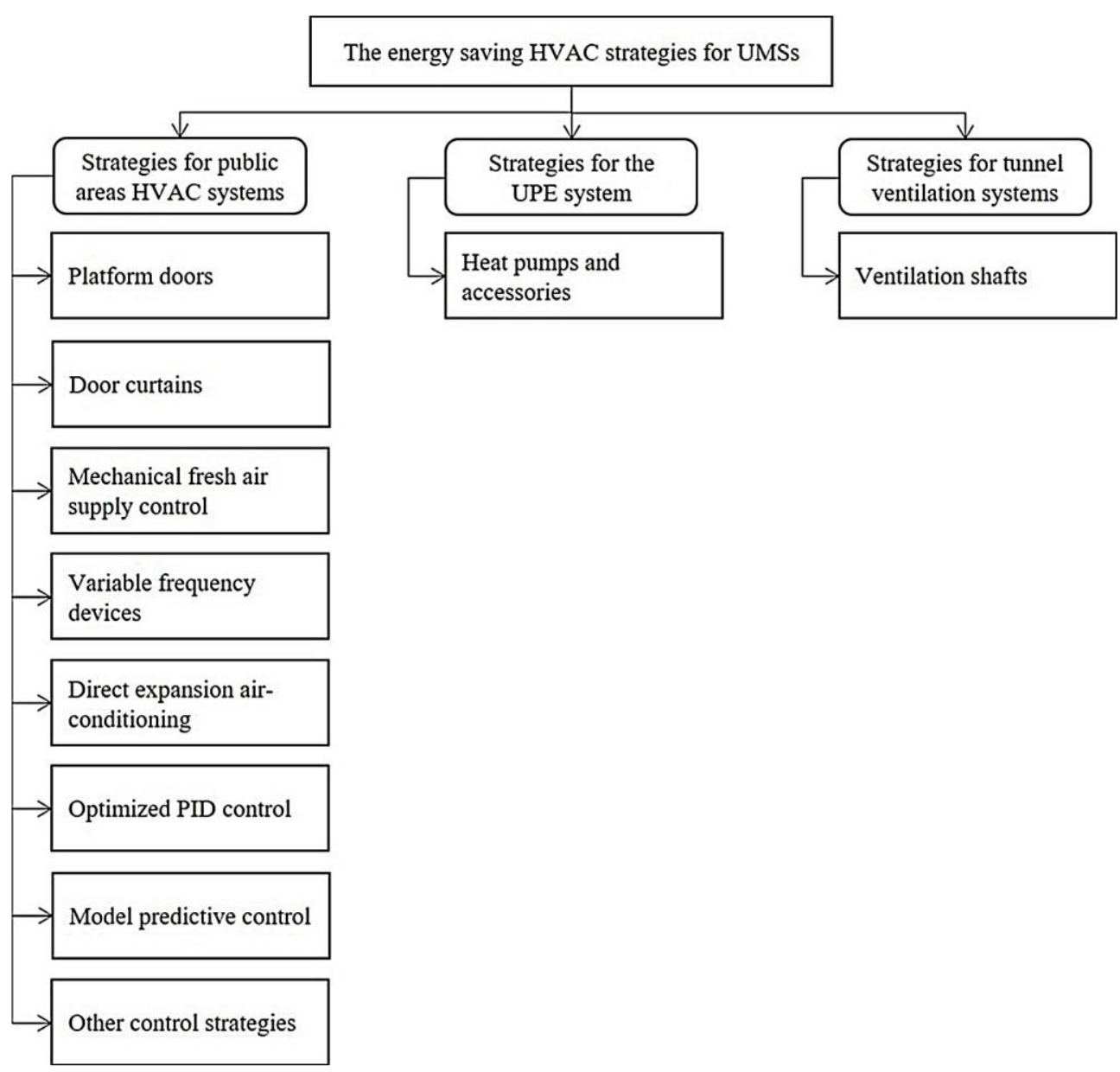

Figure 4: The energy saving HVAC strategies for UMSs.

\subsection{Energy saving strategies for the public areas HVAC system}

When developing energy saving solutions for public areas in UMSs, a major issue to tackle is the piston effect which causes the train-induced airflow. This has a significant impact on the energy efficiency of systems [51]. Figure 5 has shown the different air flow conditions when trains entering the station and when they are leaving the station. When the train is moving, positive pressure realized at the front by pushing air, and the negative pressure developed at the rear, due to the lack of air pushing away from the train [52]. When the train enters the station, air in the tunnel will be pushed into the station, and when the training leaves the station, air in the station will be sucked into the tunnels to fill the vacuum zone behind trains. 


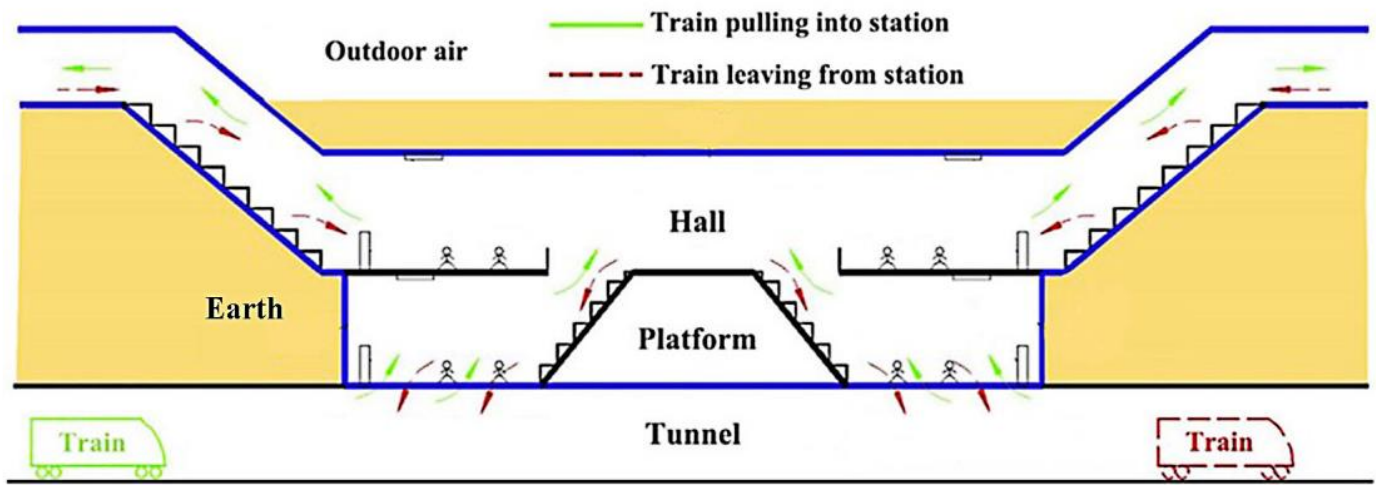

Figure 5: Air flow schematic of the piston effect in an island-type station (adapted from [53]).

\subsubsection{Platform doors}

Platform doors are a device installed on the side edge of rails in UMSs to prevent people from falling to tracks. Meanwhile, it can also help to minimize the impact of piston effect on the overall efficiency of HVAC systems in stations [42,51]. Generally, there are four types of platform doors in the market, namely, platform screen doors (PSDs), automatic platform gates (APGs), platform bailout doors (PBDs), and adjustable ventilation platform doors (AVPDs), as demonstrated in Figure 6.
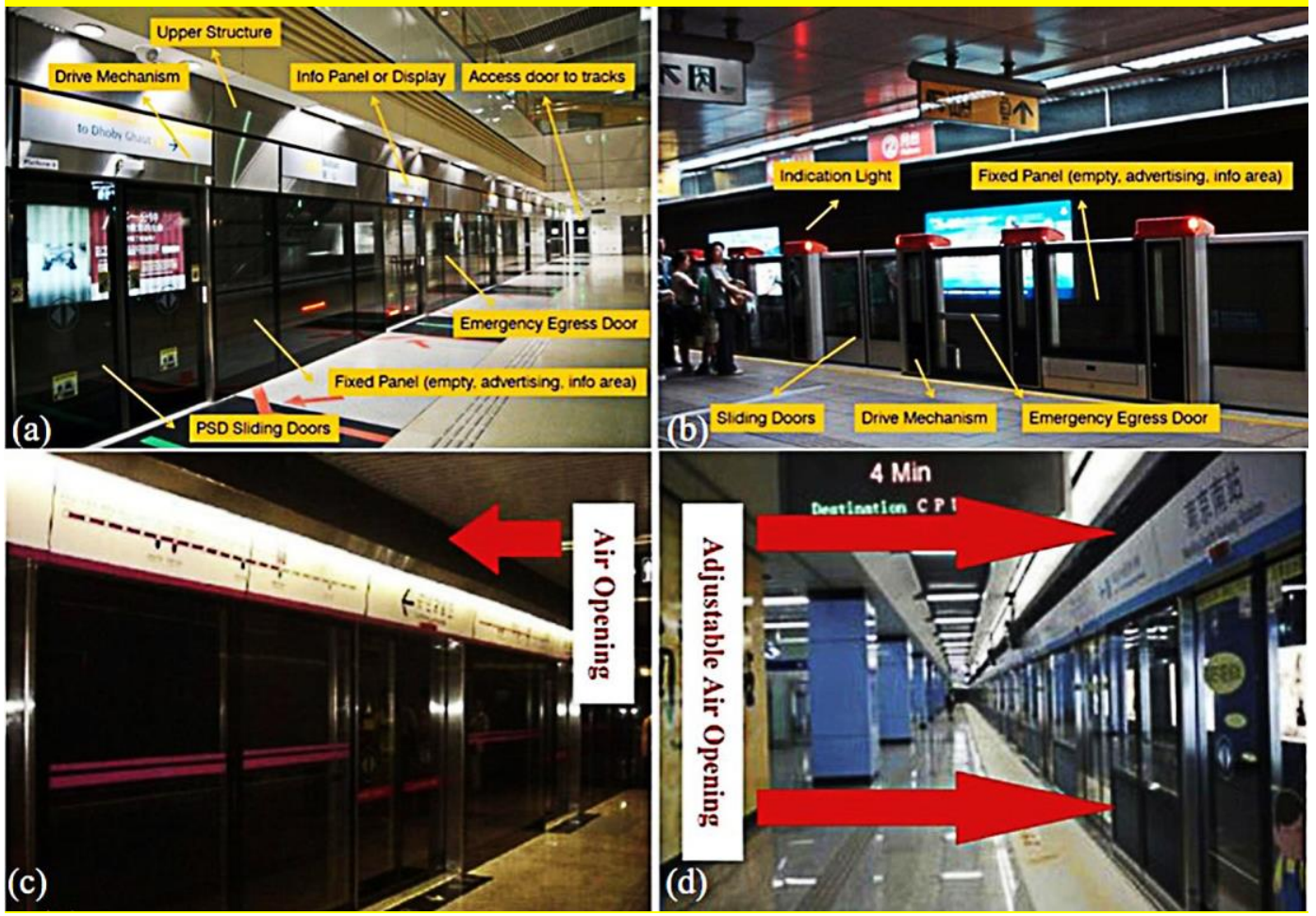

Figure 6: Platform doors in UMSs (a: PSDs; b: APGs; c: PBDs and d: AVPDs). 
PSDs are full-height glass partitions with sliding doors, which completely isolate the platform from tunnels. The contribution of PSDs to system energy efficiency mainly happens in cooling seasons, by effectively separating the platform environment from heated tunnels. When using PSDs, Hu and Lee [42] have carried out a simulation study on Taipei metro stations and observed a reduction of peak load in public areas by around $50 \%$, comparing to that without PSDs. This system, however, will increase the energy consumption of UPE fans, as the heat generated in the tunnels cannot be efficiently exhausted by the piston effect. Additionally, in non-cooling seasons, the energy consumption for station ventilation will also increase, as the airflow induced by trains cannot be utilized to provide fresh air.

APGs are chest-height sliding doors, usually with a height between $1.2-1.5 \mathrm{~m}$. The height of PBDs is often somewhere between PSDs and APGs. As both of them have the space above the door, they have the same effect on the piston wind. Their contribution to system energy efficiency is mainly by using the airflow induced by trains to cut down mechanical fresh air supply in non-cooling seasons. In northern China, the annual HVAC energy consumption of stations equipped with APGs has been found to be lower than that of PSDs by $6.4 \%$, when UPE systems operate [54].

Recently, more studies have been carried out for a new type of platform doors, namely, AVPDs. AVPDs are also full-height doors, but with adjustable air outlets at either the upper or lower part. The air outlets of AVPDs will be closed in cooling seasons to reduce heat gain from tunnels, and they will be reopened in non-cooling seasons to make full use of the airflow induced by trains for ventilation. Yang et al. [55] have created a numerical model of AVPDs and proposed an operating scheme to analyze this solution's energy saving potential in eight cities in China. Their results showed that the energysaving rate was ranging between 7.8-31.6\%. Zhang et al. [56] used computational fluid dynamics (CFD) to analyze the position, size and open angle of air outlets for optimizing the performance of AVPDs, and found that optimized AVPDs could save 20.6-60.4\% of energy compared to PBDs. Although AVPDs have been proven of having better energy performance than PSDs and PBDs, their energy performance was 
markedly influenced by local climatic conditions. For example, a study has found that the energy-saving rate of AVPDs was only $1 \%$ better than PSDs in places with hot climate and high passenger flow [57].

\subsubsection{Door curtains}

Although for most places there is no need for heating metro stations in cold seasons [18], its indoor temperature still needs to be maintained at appropriate levels [58]. This can be achieved by taking the heat released by train braking in tunnels by piston effect [59]. Adding door curtains can help to reduce the amount of cold air outdoors coming into stations from entrance. Meanwhile, it can also help to trap warm air inside stations. Ma et al. [53] have proposed a new type of door curtain with small rotation pieces, which can rotate automatically and harvest more heated air when trains drive in, as depicted in Figure 7. Their results given by the experimental model indicated that the hall temperature could be increased by $2^{\circ} \mathrm{C}$ when using this type of door curtain, compared to traditional door curtains.
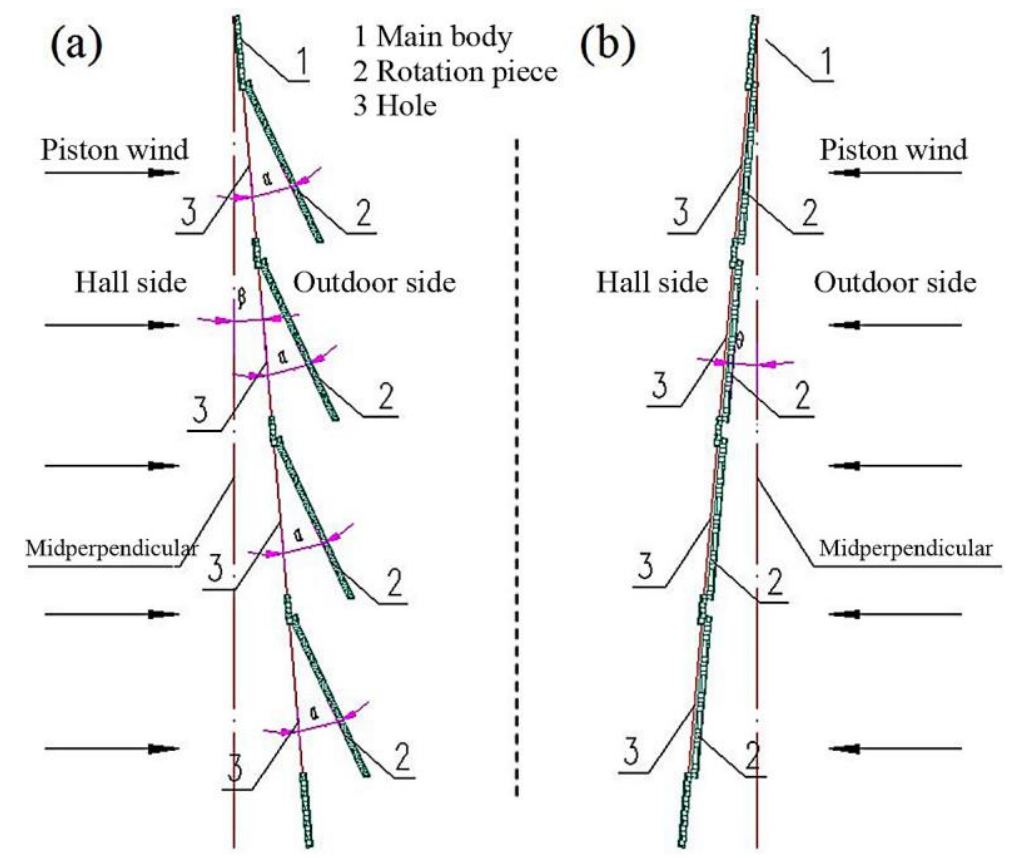

Figure 7: The new type of door curtain and its resistance component: (a) Train arriving station, (b) Train leaving station (adapted from [53]).

\subsubsection{Mechanical fresh air supply control}

Many studies have proven that an optimal control of mechanical fresh air supply can 
significantly reduce the ventilation load, due to the existence of airflow induced by trains [60-63]. By field experiments, Yang et al. [60] have found that the airflow induced by trains can help to keep $\mathrm{CO}_{2}$ concentration in an appropriate range in most cases. Wang and Li [12] have proposed a method to simulate train-induced airflow, with a calculated airflow rate between 4.1-13.2 $\mathrm{m}^{3} / \mathrm{s}$ under a resistance coefficient of PSDs between 0.11-0.35. Based on these results, they suggested that most UMSs in China no longer require mechanical fresh air if train-induced airflow can be used effectively. And this could help to save 3-23\% energy consumption by the HVAC systems [64]. Guan et al. [38] have suggested to use a return air alone condition for ventilation, as illustrated in Figure 8. Under this condition, the outdoor air fan would be switched off but with damper V3 on, damper V1 off and damper V2 off, to utilize train-induced air for fresh air supply. When using this solution, the electricity consumption of the ventilation system was reduced by $10-20 \%$ in cooling seasons, compared to normal ventilation conditions. Similarly, in Nobosibirsk, Russia, Krasyuk [65] mentioned that the piston effect allowed effective ventilation of shallow stations without switching on fans when the outdoor air temperature was lower than $8^{\circ} \mathrm{C}$.

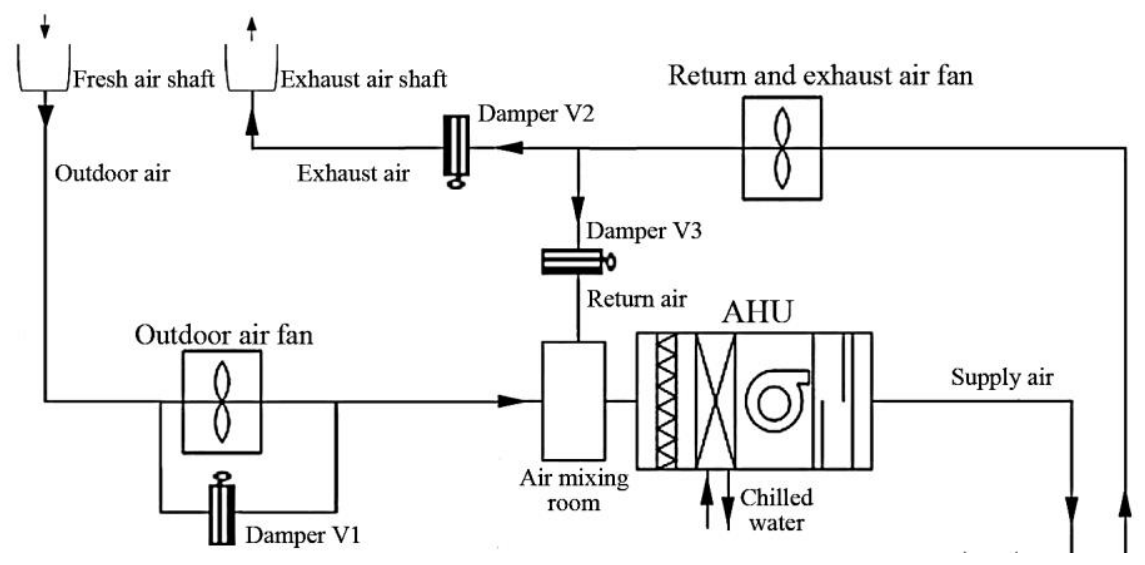

Figure 8: Air flow pattern in ventilation systems.

The mechanical fresh air supply control using piston wind to reduce the energy consumption of the mechanical ventilation system is easy to implement and can bring reliable energy-saving benefits. However, it is also a need to guarantee the train-induced air quality when using the piston wind to save energy from the mechanical ventilation system. 


\subsubsection{Variable frequency devices (VFDs)}

Reducing the transportation energy required in HVAC systems is also one way of getting better energy performance. A field investigation in ten stations in Beijing has shown that the coefficient of performance $(\mathrm{CoP})$ of refrigerators in the monitored stations were at 4.4 in average. However, due to the energy consumed by fans, pumps and cooling towers, the average energy efficiency ratio and the seasonal coefficient of performance were $27 \%$ and $48 \%$ respectively lower than the average CoP [46]. Yang et al. [17] have analyzed the operation condition of chilled-water pumps and fans with frequency conversion technologies and observed total power saving ratios ranging from 59.5-73.4\%. Motors with inverters to enable variable speed operation of fans, as shown in Figure 9, have been suggested as an alternative to enhance the performance of ventilation systems [66]. Hu et al. [47] performed a study based on simulation for using variable frequency control for UPE fans in tropical climate, and obtained results showing that this solution could save $70-83 \%$ of electricity consumption, comparing to traditional control methods. The VFDs have been proven to be a reliable means of energy saving, with economic advantages in the long run, but the premise is based on a stable control strategy.

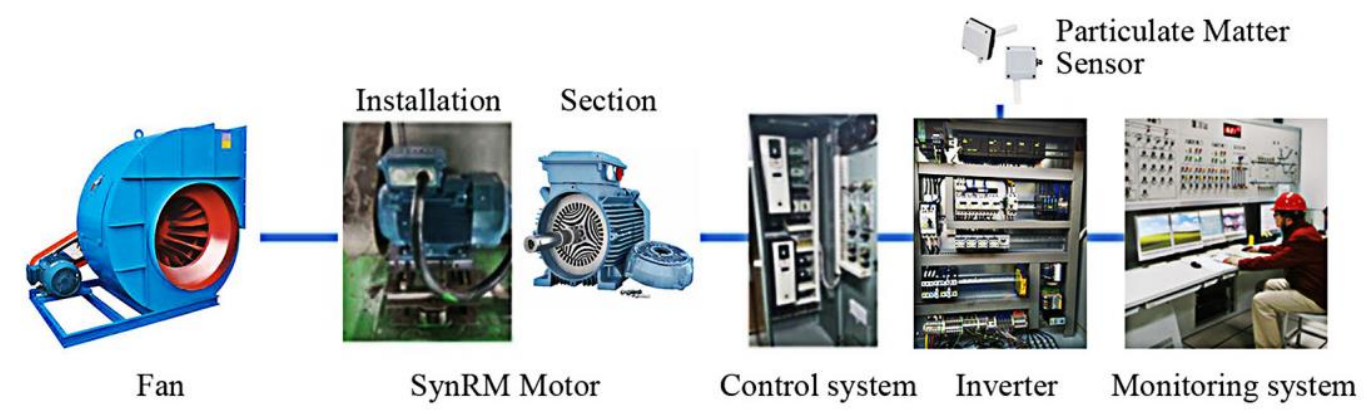

Figure 9: Ventilation system with inverter equipped in metro stations (adapted from [66]).

\subsubsection{Direct expansion air-conditioning $(D X A / C)$}

Figure 10 has shown the schematic diagram of another solution, called direct expansion air-conditioning system. In this solution, the refrigerant is evaporated in the cooling coils by absorbing heat in the supply airflow instead of chilled water. This system 
eliminates chilled water systems and relevant pipes, helping to save initial cost and operating energy consumption.

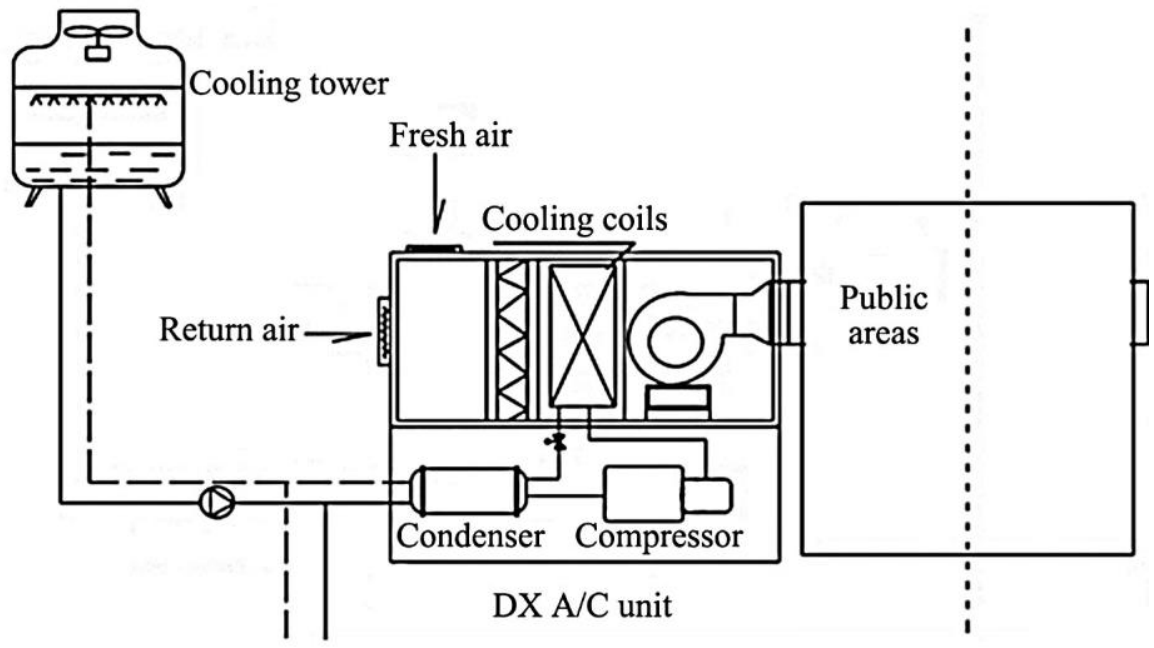

Figure 10: A schematic diagram for DX A/C systems.

A recent study has used DX A/C and evaporative condensers together in UMSs [67], the evaporative condenser of the system is working collaboratively with the fan installed on the wall to ensure the condensation effect. Comparing to traditional systems, the novel system is a refrigerant direct-expansion system, which can save both energy and space. Due to the removal of cooling towers, this system can also solve issues in terms of both noise and water leakiness. Additionally, the condensing temperature can be decreased due to direct expansion, hence increasing the system's CoP. An economic model has been applied to analyze the effect of using this solution in Beijing, and the results showed that it saved energy by up to $81,022 \mathrm{kWh}$ annually, equaling to $11 \%$ of the energy consumption by conventional systems [67]. However, the operation performance of this system is affected by the changing external conditions, such as the air relative humidity and velocity on the condenser side, which limits its operational stability.

\subsubsection{Optimized proportional-integral-derivative (PID) control}

It has been well proven that implementing advanced control strategies can promote the performance of HVAC systems, in terms of both energy and occupant comfort $[68,69]$. 
Therefore, many studies have devoted to developing optimized PID control strategies for UMS ventilation systems. Their solutions mainly considered error dynamics and modulated controlled variables to understand the dynamically changing indoor environment in UMSs. Kim et al. [70] have compared the performances of four PI (proportional-integral)-based control strategies, namely, 1) feedback (FB) control only, 2) combining one $\mathrm{FB}$ and one feedforward $\left(\mathrm{FF}_{1}\right)$ control (used to control the disturbance effects of the subway schedule), 3) combining one $\mathrm{FB}$ and one feedforward $\left(\mathrm{FF}_{2}\right)$ controls (used to control disturbance effects of the outdoor PM10 by handling the ventilation inverter frequency) and 4) combining one FB and two FF controls. The FB controller controlled $\mathrm{PM}_{10}$ concentration by regulating the frequency of ventilation inverters to meet the set points. The results indicated that the solution with one FB and two FF controls gave the best energy saving performance. With further tuning of control parameters [71,72], the improved gain scheduling control system, as depicted in Figure 11 , was proven to reduce energy consumption by up to $9 \%$ when compared to traditional control methods. Upon this solution, Li et al. [73] added an FF controller to consider the influence of passengers and a multi-objective genetic algorithm for automatically updating the system optimal set-points, with an noticed $10.3 \%$ reduction in ventilation systems.

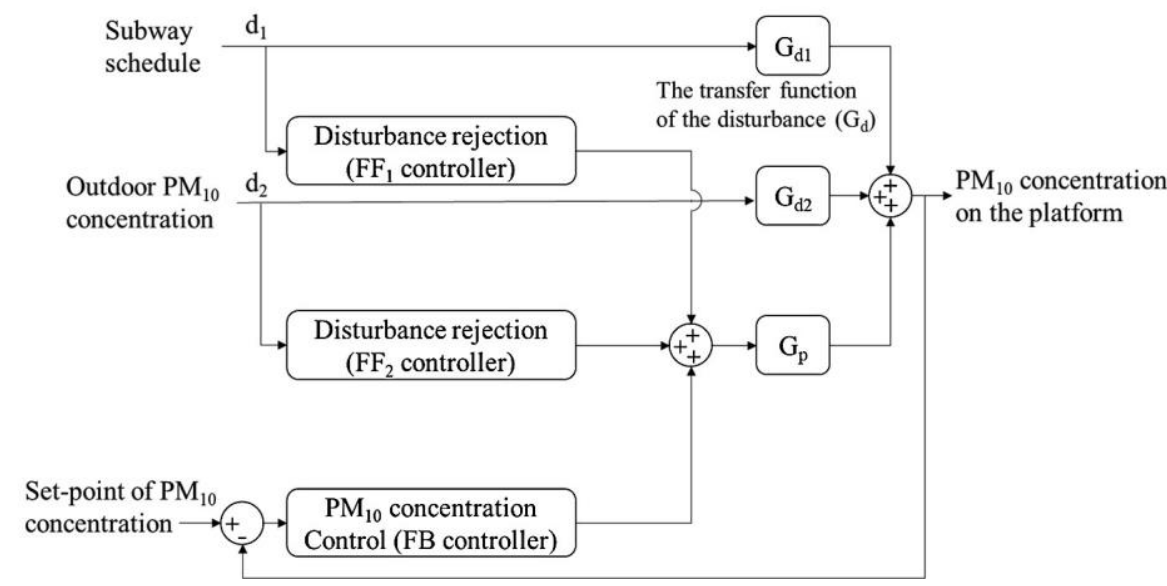

Figure 11: Block diagram of the ventilation control system for the metro station (adapted from [72]).

Lee et al. [74] have also developed a ventilation control algorithm based on PID control. 
After re-tuning the proportional gain of PID controllers by a line-searching algorithm, the optimized control structure showed a $36 \%$ reduction in energy demand when compared to the open-loop structure. Kim et al. [75] implemented iterative dynamic programming into the control of ventilation systems to decide the optimal set-points, and the system reduced the energy consumption by $4.6 \%$ comparing to schedule-based systems. According to these studies, the optimized PID control for ventilation systems can be classified into three categories, namely, adding control modules for different disturbances, tuning the control parameters, and optimizing the control set-points. These optimization measures are universal and can be extended to different types of public infrastructures including airports and coach stations, without a priori knowledge and human intervention.

\subsubsection{Model predictive control (MPC)}

MPC is a promising control approach for HVAC systems, because of its ability of optimizing both linear and non-linear multi-input/multi-output processes, with explicit consideration of potential constraints [69]. In 2011, one European Union project (Sustainable energy management for underground stations, SEAM4US) developed an intelligent energy management system to reduce electricity consumption of metro stations [18,76-80]. This system is based on an MPC algorithm coupled with a monitoring network. The MPC algorithm was based on a Bayesian environmental prediction model (using weather data predicted by a weather forecast web service), an occupancy detection system, and schedule-based determinations of train arrivals and fan operations. As the MPC approach allows earlier actions to change system settings, in a case study carried out in Barcelona, it helped to achieve an energy saving greater than $30 \%$.

Rigaut et al. [81] have presented an MPC-based strategy for the optimal management of a microgrid, which connects regenerative braking energy sources, HVAC systems and electricity storage systems in metro stations. Liu et al. [19] utilized a multiobjective genetic algorithm to optimize MPC setpoints and achieved a $24 \%$ energy 
saving compared to schedule-based control. Nevertheless, the stability of these MPC systems may become difficult to maintain with more complex control algorithms [69]. For example, the predictive model in the MPC is usually a grey box system based on both simulation model and field tests. If the real situation is beyond its design conditions, such as in cases of extreme climate or building retrofitting, the control accuracy will lose guarantee. Thus, the system needs updating control models at certain time intervals.

\subsubsection{Other control strategies}

Other control strategies, such as adaptive control and reinforcement learning control, $[82,83]$ have also been applied in existing studies. Wang et al. [84] retrofitted HVAC control systems in UMSs based on distributed control architecture with centralized management. Both adaptive control and schedule-based policies were developed according to the components of HVAC systems, and helped to reduce the energy consumption of stations between $20-38 \%$. Heo et al. [82] have proposed a data-driven approach for a ventilation control system based on a deep reinforcement learning algorithm. The algorithm agent was trained in a virtual environment developed based on a gray-box model, and their results showed that the control system could reduce the energy consumption by up to $14.4 \%$ for the validation dataset. The deep reinforcement learning algorithm, however, took an unacceptably long time to learn the data and therefore was difficult to ensure stability and efficiency in real practice.

It should be noted that the operation of these intelligent control systems is based on a large-scale monitoring system, which contains various sensors and actuators. The wireless sensor network has been increasingly used in UMSs for connecting a control system with different devices, and this will increase both initial investment and maintenance costs $[18,85,86]$.

\subsection{Energy saving strategies for the UPE system}

For underground metro networks, the heat absorbed by the earth surrounding an underground tunnel can account for $30 \%$ of the total heat lost $[87,88]$. The heat energy provided by tunnels could potentially be captured, transferred, and utilized by heat 
pumps. The use of heat pumps may lead to energy conservation in heating as they can perform between 2-4 times more efficiently than electrical resistors [20]. Moreover, heat pumps can help cool the tunnel and reduce the UPE energy consumption as well.

Common sources of heat for heat pumps used for UMSs include air, ground, and water. The work done by Ninikas et al. [89] found a relatively stable temperature (average temperature during winter $=15^{\circ} \mathrm{C}$, annual variation $=2.6^{\circ} \mathrm{C}$ ) and enough air movement inside the tunnels of the metro system in Glasgow through field tests, and decided to use this character to collect heat from tunnel air for space heating and domestic hot water. The energy consumption of air source heat pumps (ASHPs) is expected to be $75 \%$ less than existing electric fired heating systems. Davies et al. [90] have proposed an air source recovery method through the ventilation shafts of London underground tunnels (see Figure 12 left), and this system can simultaneously provide $900 \mathrm{~kW}$ cooling to the tunnel and 1.1 MW heat for local district networks.

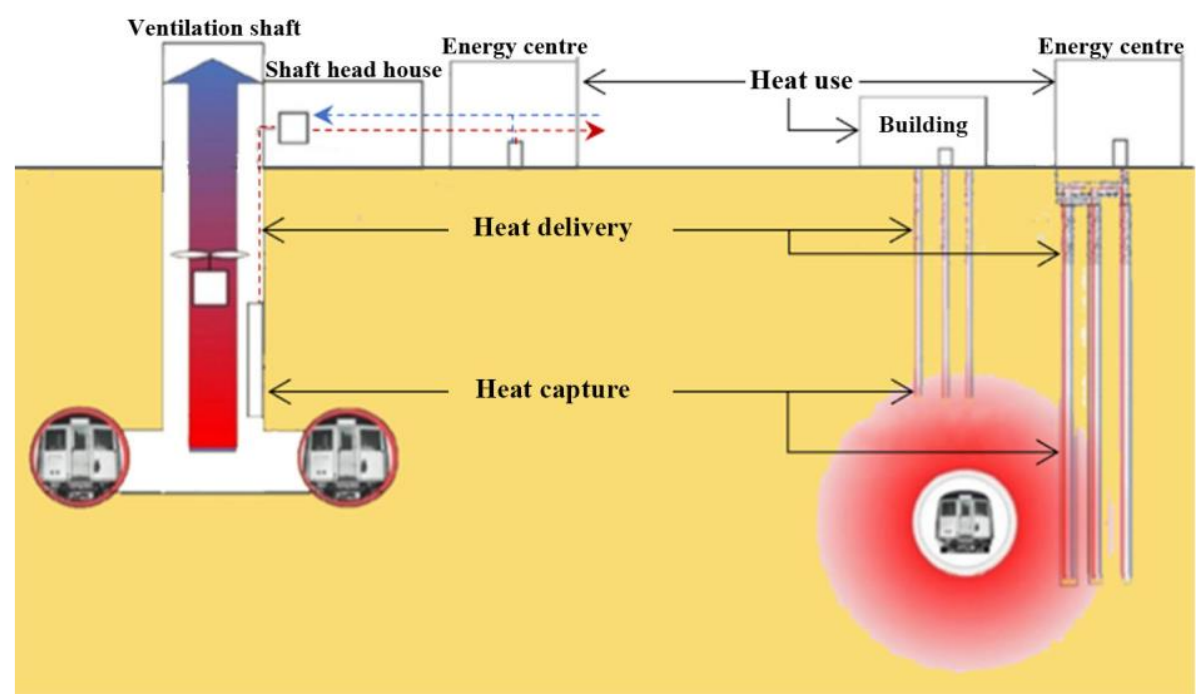

Figure 12: Heat recovery from tunnel air (left) and ground (right) (adapted from [87]).

Besides recovering heat from tunnel air, energy has been recovered by external ground loops as well, as shown in Figure 12 (right). Revesz et al. [87] have reviewed the interactions between ground source heat pumps (GSHPs) and urban underground tunnels, and pointed out that underground tunnels were appropriate heat sources for nearby heat pumps. Mortada et al. [91] presented a simulation framework for 
quantifying the amount of heat that can be extracted from overheated subway tunnels using geothermal heat exchangers. Their results showed that the depth of $15 \mathrm{~m}$ below the tunnel was sufficient for vertical closed-loop heat exchangers to yield a temperature drop of $4^{\circ} \mathrm{C}$ in the metro stations in London, and a single tunnel bore-hole's annual heat extraction could be about $9336 \mathrm{kWh}$, equaling to the average annual heat demand of one UK household.

There are also attempts to use groundwater as a direct cooling source for stations [92] and water source heat pumps (WSHPs) to recovery heat energy from tunnel waste water for heating and domestic hot water [93-95]. Ninikas et al. [95] installed a WSHP at St. George's Cross station in Glasgow, using subsurface wastewater to heat all offices at the station. In the study, they realized a $60 \%$ energy usage reduction of the heating system, against the value of the old heating system. Although the use of WSHPs and GSHPs can recovery a great amount of heat, these systems are more complex and expensive than AHSPs, and their applications are restricted by geographical conditions.

Meanwhile, some researchers also tried to promote terminal heat exchangers to enhance the overall performance of GSHPs. Thompson et al. [96] have evaluated the possibility of strengthening ground cooling using heat pipes for UMSs using a model experiment. This was further explored by Brandl [97], who combined heat pipes with heat pumps for heating and cooling stations in Vienna, as shown in Figure 13. Similar studies were carried out in northern China as well [98-100], where Zhang et al. [98] conducted an experimental study on the thermal performance of tunnel lining ground heat exchangers. They indicated that the inlet temperature and the flow rate of heat exchange medium and heat exchange pipe distance were important parameters affecting the heat exchange rate of heat exchangers. Capillary heat exchangers have also been used in underground tunnels to promote heat exchange recently, and their performance has been investigated in some numerical studies [101-104]. These studies simulated the heat transfer performance of the capillary with different influencing factors, including water flow velocity, initial temperature of surrounding rock and tunnel air temperature, etc., but the energy-saving potential of this heat exchanger has still not been quantified. 

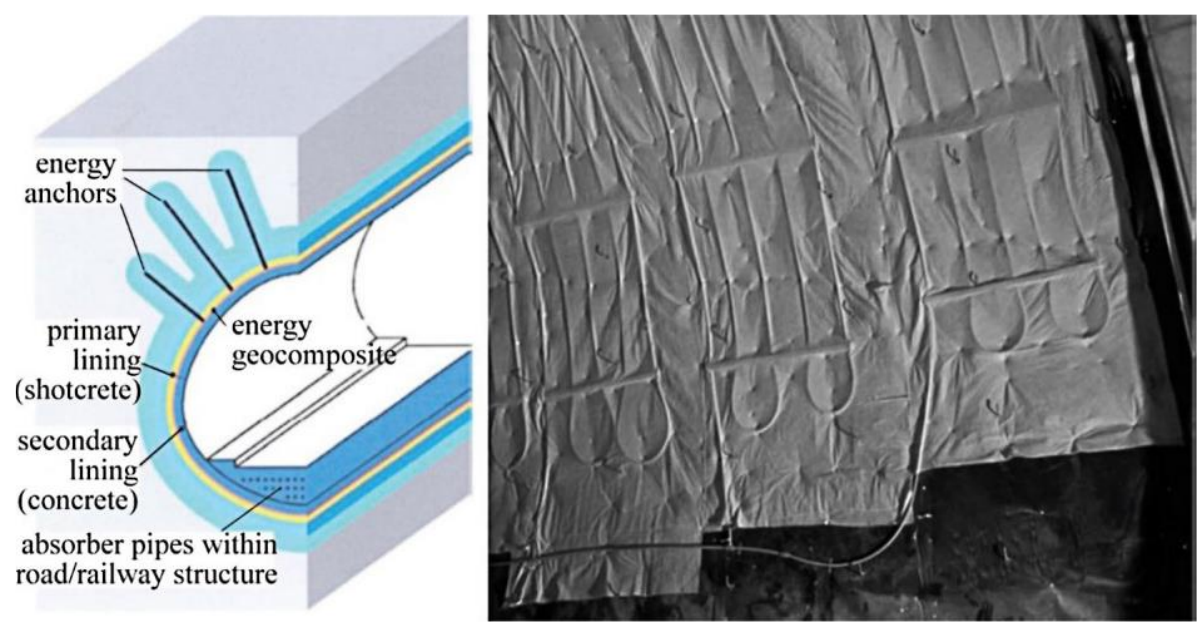

Figure 13: Schematic of an energy tunnel (adapted from [97]).

\subsection{Energy saving strategies for the tunnel ventilation system}

Since a large part of the cooling load in stations is from the train movement in tunnels, cooling tunnel environment will effectively reduce the burden of HVAC systems in UMSs [105]. A reasonable design of ventilation shafts can help to improve tunnel ventilation with minimized energy input.

Ke et al. [50] have explored the impact of various ventilation operating strategies in metro environment for optimizing the design of HVAC systems. From the study, they concluded that the cross-sectional area of ventilation shafts was quite more effective on ventilation volume than length, with $40 \%$ more airflow rate achieved by doubling crosssectional area. González et al. [49] presented a numerical study based on a dynamic mesh technique to simulate the influence of piston effect in longitudinal ventilation systems of metro tunnels, with an estimated overall energy saving between $2.5-3.0 \%$, taking into account the airflow caused by train movement. Using a three-dimensional numerical analysis, Kim and Kim [106] analyzed the effect of duct location on the ventilation performance in one metro tunnel and evaluated the ventilation efficiency of PSDs. From the study, they suggested the optimum location of the vent shaft giving maximum ventilation performance lies near the upstream of the station. 


\section{Discussion and future work}

Although current existing HVAC systems in UMSs can exhaust redundant heat and provide fresh air, it is not enough to achieve metro environmental control solely based on providing adequate capacity to satisfy given criteria $[25,107]$. On the contrary, it is necessary to achieve the overall optimization of the entire HVAC system. The design objectives ought to be geared to obtain the most efficient utilization of economic and natural resources. Existing studies have designed or developed various HVAC strategies to meet these goals and each HVAC discipline has specific design requirements and presents opportunities for saving energy. To promote their applications in UMSs, this section has compared the mechanisms and the energy saving potential of these strategies, and proposed future research directions based on this analysis.

\subsection{Classification based on operational mechanisms}

The use of platform doors, door curtains and ventilation shafts are mainly based on changing the geometry (resistance) of the piston airflow path, and thus to control the airflow rate of piston wind in public areas or tunnels. To avoid energy waste, mechanical fresh air supply control, VFDs, optimized PID control, MPC and other control strategies are mainly based on demand control strategy. DX A/C uses refrigerant to directly absorb heat from fresh air and save cost in the cooling part by changing configurations. ASHPs use the relatively stable environment inside tunnels to improve systems' CoP. GSHPs and WSHPs recover heat energy from ground and subsurface water around metro tunnels, respectively. Heat pipes and capillary heat exchangers enhance the heat exchange between tunnels and earth by increasing heat exchange area.

In the view of building energy conservation, platform doors, door curtains and ventilation shafts can be considered as passive strategies because they use energy in natural environment (train-induced airflow) to air-condition the indoor environment of stations, so should be preferred in real applications [108]. Active strategies, which consume energy to satisfy the needs of cooling/heating buildings, can be classified into two classes: 1) energy-efficient HVAC equipment, such as VDFs, DX A/C and heat 
pumps; and 2) advanced control systems, like the system based on the demand control strategy.

\subsection{Comparison of energy performance}

Finding out the most appropriate HVAC system for a given UMS is a complex evaluation process that requires a detailed analysis on energy considering various influential factors. Table 3 lists three aspects relevant to evaluating the energy saving potential of reviewed strategies. For the environmental criteria, only the MPC can control temperature, $\mathrm{CO}_{2}$, and $\mathrm{PM}$ concentration simultaneously. Additionally, most control strategies aim at controlling ventilation systems to regulate temperature, rather than controlling air conditioning systems. It can also be seen that when passive strategies are used, there is usually a lack of control on the concentration of PMs. For study methods, the simulation method is dominantly used, with validation against field measured data. This is excusable as full-scale experimental models are generally costly in both finance and time [109]. However, in terms of simulation, the main simulation tool is design for the station thermal environment rather than systems' energy consumption. For energy performance, the energy-saving potentials of these strategies showed great differences, and the same strategy even performed differently in different studies. A possible explanation is because of the various influential factors and different benchmarks in complex metro systems.

\subsection{Future work}

According to the review work carried out in this study, some notes have been proposed for saving HVAC energy demand in UMSs, to better underpin future energy analysis. They include 1) when using train-induced air for ventilation, it is necessary to consider the impact of both tunnels and outdoor air quality on stations' IAQ; 2) energy models or evaluation systems for underground stations are still needed for evaluating the energy performance of each strategy under standard conditions; 3) with energy recovery when running metro trains, such as using regenerative braking and energy-saving slope technologies, the amount of heat dissipated in tunnels will be reduced, affecting the 
environments both in tunnels and stations; 4) since most studies on energy conservation strategies are still in pilot or a modelling stages, more studies are needed to justify their actual impact in real situations. 


\section{Table 3}

Energy saving potential of the reviewed strategies for UMSs.

\begin{tabular}{|c|c|c|c|c|}
\hline Category & $\begin{array}{l}\text { Environmental } \\
\text { criteria }\end{array}$ & Study methods & Energy saving rate & Ref. \\
\hline PSDs & Temperature, $\mathrm{CO}_{2}$ & $\begin{array}{l}\text { Simulation (SES, carrier E20- } \\
\text { II) with on-site measurements }\end{array}$ & $\begin{array}{l}\text { The peak load for the case with PSD is only around } 50 \% \text { of that for the } \\
\text { case without PSD }\end{array}$ & [42] \\
\hline $\begin{array}{l}\text { APGs and } \\
\text { PBDs }\end{array}$ & Temperature, $\mathrm{CO}_{2}$ & $\begin{array}{l}\text { Simulation (Energy Plus) with } \\
\text { on-site measurements }\end{array}$ & $\begin{array}{l}\text { The annual air conditioning and ventilation energy consumption of APG } \\
\text { is lower than that of PSD system by } 6.4 \%\end{array}$ & {$[54]$} \\
\hline AVPDs & Temperature, $\mathrm{CO}_{2}$ & $\begin{array}{l}\text { Simulation (CFD, STESS, } \\
\text { IDA) with on-site } \\
\text { measurements }\end{array}$ & $\begin{array}{l}\text { 1-20\% compared with PSD system } \\
\text { 7.8-31.6\% compared with PSD system } \\
\text { 20.64-60.43\% compared with PSD system }\end{array}$ & $\begin{array}{l}{[57]} \\
{[55]} \\
{[56]}\end{array}$ \\
\hline Door curtains & Temperature & $\begin{array}{l}\text { Simulation (IDA) with on-site } \\
\text { measurements }\end{array}$ & The hall temperature would increase $2^{\circ} \mathrm{C}$ & {$[53]$} \\
\hline $\begin{array}{l}\text { Mechanical } \\
\text { fresh air supply } \\
\text { control }\end{array}$ & $\mathrm{CO}_{2}$ & $\begin{array}{l}\text { Simulation (STESS) with on- } \\
\text { site measurements }\end{array}$ & $\begin{array}{l}9.9 \% \text { and } 19.6 \% \text { in two stations under the return air alone condition } \\
\text { If the mechanical fresh air supply is abandoned, there would be } 3-23 \% \\
\text { energy saving of the HVAC system }\end{array}$ & [38] \\
\hline VFDs & Temperature, $\mathrm{CO}_{2}, \mathrm{PM}$ & $\begin{array}{l}\text { Theoretical calculation and } \\
\text { simulation }\end{array}$ & $59.5-73.4 \%$ & {$[17]$} \\
\hline $\mathrm{DX} \mathrm{A} / \mathrm{C}$ & Temperature & On-site measurements & $11 \%$ when combined with the evaporative condenser & {$[67]$} \\
\hline
\end{tabular}




\begin{tabular}{|c|c|c|c|c|}
\hline $\begin{array}{l}\text { Optimized PID } \\
\text { control }\end{array}$ & $\mathrm{PM}$ & $\begin{array}{l}\text { Simulation (MATLAB) with } \\
\text { on-site measurements }\end{array}$ & $4.6-36 \%$ & {$[73-75]$} \\
\hline MPC & Temperature, $\mathrm{CO}_{2}, \mathrm{PM}$ & $\begin{array}{l}\text { Simulation (MATLAB, CFD) } \\
\text { with on-site measurements }\end{array}$ & $24-33 \%$ & {$[18,19]$} \\
\hline ASHPs & Temperature & On-site measurements & $75 \%$ less compared with the existing electric fired heating system & [89] \\
\hline GSHPs & Temperature & $\begin{array}{l}\text { Simulation (MATLAB, IDA) } \\
\text { with on-site measurements }\end{array}$ & The heat from the tunnel per meter is $3100 \mathrm{kWh} / \mathrm{m}$ & [91] \\
\hline WSHPs & Temperature & $\begin{array}{l}\text { Theoretical calculation and on- } \\
\text { site measurements }\end{array}$ & $60 \%$ energy input reduction for the heating system & {$[95]$} \\
\hline Heat pipe & Temperature & Theoretical calculation & Reduction natural gas costs on $34,000 \mathrm{~m}^{3}$ per year & [97] \\
\hline $\begin{array}{l}\text { Capillary heat } \\
\text { exchanger }\end{array}$ & Temperature & $\begin{array}{l}\text { Simulation (MATLAB, } \\
\text { TRNSYS) }\end{array}$ & The heat transfer characteristics are studied but no energy saving results & {$[101,104]$} \\
\hline $\begin{array}{l}\text { Ventilation } \\
\text { shafts }\end{array}$ & Temperature & Simulation (CFD, STESS, SES) & $2.5-3 \%$ & [49] \\
\hline
\end{tabular}




\section{Conclusions}

UMSs are rapidly developing, and their energy consumption is considerably growing. The HVAC systems used in UMSs are key energy consumers, so have received increasing attention from researchers in the world. This review work has summarized major design features of HVAC systems in UMSs and identified issues affecting their energy efficiency. A systematic review on recent novel energy saving HVAC strategies for UMSs has been presented in this paper, with a total number of ten different strategies. From the review work, main conclusions have been drawn as followings:

(1) Platform doors, ventilation shafts and door curtains are classified as passive strategies related to using the train-induced air, and they are preferred for designing energy efficient UMSs. From the aspect of active strategies, heat pumps used to recover heat from the UMSs are becoming a trend in the research community, especially geothermal technologies. The DX A/C is another promising option for air conditioning energy saving. However, the actual energy performance of these two types of technologies is usually greatly affected by the actual operating conditions. In comparison, the application of VFDs is one of the most reliable energy-saving ways among the active strategies.

(2) For the existing HVAC systems in UMSs, the implementation of operational measures is normally preferred to the introduction of new technologies, as significant energy savings can be achieved with relatively low investment costs and minor modifications. Thus, adopting advanced control strategies have been identified as the most promising solutions for those systems. Currently, these strategies are continually being proposed for their vital ability to reduce the energy use of HVAC systems in longterm running. Among them, the algorithm-based approaches are effective based on the careful design and maintenance of the system. On the other hand, reducing the mechanical fresh air supply has been proved an easy-to-operate control strategy with appropriate cost and it is recommended along with the passive strategies and VFDs. 
(3) Although various energy saving strategies have been proposed for the HVAC systems of underground stations, there are still limitations identified in the study for different reasons. To better underpin the future energy analysis of the reviewed strategies, four suggestions were proposed for the future evolution of the HVAC system. Additionally, based on the proved energy-saving potential of existing strategies, it can be inferred that the continuous improvement of the HVAC energy-saving strategies will make greater contributions to the reduction of energy consumption and carbon emissions of the ever-expanding urban metro networks.

\section{Declarations of interest}

None.

\section{Acknowledgements}

This work was supported by the National Key Research Program of China (No.2018YFC0705000). We would like to thank Dr. Fan Man, and two anonymous reviewers and the editors of Renewable and Sustainable Energy Reviews for their helpful comments and suggestions. Permission has been granted for use of figures in the paper.

\section{References}

[1] UITP (International Association of Public Transport), World Metro Figures 2018, https://cms.uitp.org/wp/wp-content/uploads/2020/06/Statistics-Brief-World-metro-figures2018V3_WEB.pdf; 2020 [accessed 12 October 2020].

[2] Ahn J, Cho S, Chung DH. Development of a statistical analysis model to benchmark the energy use intensity of subway stations. Appl Energy 2016;179:488-96. https://doi.org/10.1016/j.apenergy.2016.06.065.

[3] Hong W, Kim S. A study on the energy consumption unit of subway stations in Korea. Build Environ 2004;39:1497-503. https://doi.org/10.1016/j.buildenv.2004.04.008.

[4] Park JH, Son YS, Kim KH. A review of traditional and advanced technologies for the removal of particulate matter in subway systems. Indoor Air 2019;29:177-91. https://doi.org/10.1111/ina.12532.

[5] Martins V, Moreno T, Mendes L, Eleftheriadis K, Diapouli E, Alves CA, et al. Factors controlling air quality in different European subway systems. Environ Res 2016;146:35-46. https://doi.org/10.1016/j.envres.2015.12.007.

[6] Brüne M, Charlton J, Pflitsch A, Agnew B. The Influence of subway climatology on gas dispersion and the effectiveness of guided evacuations in a complex subway station. Meteorol 
Zeitschrift 2016;25:489-99. https://doi.org/10.1127/metz/2016/0726.

[7] Wang L, Du Z, Zhang J, Chen R, Yu S, Qu M. Study on the thermal comfort characteristics under the vent with supplying air jets and cross-flows coupling in subway stations. Energy Build 2016;131:113-22. https://doi.org/10.1016/j.enbuild.2016.09.012.

[8] González-Gil A, Palacin R, Batty P. Optimal energy management of urban rail systems: Key performance indicators. Energy Convers Manag 2015;90:282-91. https://doi.org/10.1016/j.enconman.2014.11.035.

[9] Leung PCM, Lee EWM. Estimation of electrical power consumption in subway station design by intelligent approach. Appl Energy 2013;101:634-43. https://doi.org/10.1016/j.apenergy.2012.07.017.

[10] Guan B, Liu X, Zhang T, Xia J. Energy consumption of subway stations in China: Data and influencing factors. Sustain Cities Soc 2018;43:451-61. https://doi.org/10.1016/j.scs.2018.09.018.

[11] Lin L, Liu X, Zhang T, Liu X. Energy consumption index and evaluation method of public traffic buildings in China. Sustain Cities Soc 2020;57:102132. https://doi.org/10.1016/j.scs.2020.102132.

[12] Wang Y, Li X. Unorganized ventilation in subway stations with Platform Screen Doors. Build Environ 2017;125:556-64. https://doi.org/10.1016/j.buildenv.2017.09.009.

[13] Casals M, Gangolells M, Forcada N, Macarulla M, Giretti A. A breakdown of energy consumption in an underground station. Energy Build 2014;78:89-97. https://doi.org/10.1016/j.enbuild.2014.04.020.

[14] Fu K, Deng Z. Current Situation of Energy Consumption in Guangzhou Railway Station and Analysis on the Potential of Energy Conservation. vol. 2. 2009. https://doi.org/10.5539/jsd.v2n1p117.

[15] Anderson RJ, Findlay NS, Graham DJ. Maximising the potential for metros to reduce energy consumption and deliver low-carbon transportation in cities. Transp Res Board 91st Annu Meet 2012:1-13.

[16] Zhang H, Cui T, Liu M, Zheng W. Energy performance investigation of an innovative environmental control system in subway station. Build Environ 2017;126:68-81. https://doi.org/10.1016/j.buildenv.2017.09.023.

[17] Yang Z, Yu Z, Yu L, Ma F. Research on frequency conversion technology of metro station's ventilation and air-conditioning system. Appl Therm Eng 2014;69:123-9. https://doi.org/10.1016/j.applthermaleng.2014.04.016.

[18] Vaccarini M, Giretti A, Tolve LC, Casals M. Model predictive energy control of ventilation for underground stations. Energy Build 2016;116:326-40. https://doi.org/10.1016/j.enbuild.2016.01.020.

[19] Liu H, Lee S, Kim M, Shi H, Kim JT, Wasewar KL, et al. Multi-objective optimization of indoor air quality control and energy consumption minimization in a subway ventilation system. Energy Build 2013;66:553-61. https://doi.org/10.1016/j.enbuild.2013.07.066.

[20] González-Gil A, Palacin R, Batty P, Powell JP. A systems approach to reduce urban rail energy consumption. Energy Convers Manag 2014;80:509-24. https://doi.org/10.1016/j.enconman.2014.01.060.

[21] American Society of Heating Ventilating and Air Conditioning Engineers. Thermal Environmental Conditions for Human Occupancy. ASHRAE Stand. 55-2004, Atlanta, GA, 
USA: 2004.

[22] Parsons K. Human thermal environments: The effects of hot, moderate, andcold environments on human health,comfort, and performance, Third edition. 2014.

https://doi.org/10.1201/b16750.

[23] International Organization for Standardization. ISO Standard 7730. Moderate Thermal Environment, Determination of PMV and PPD Indices and Specifications of the Conditions for Thermal Comfort. Geneva, Switzerland: 2005.

[24] BSI. 2007 Indoor Environmental Input Parameters for Design and Assessment of Energy Performance of Buildings Addressing Indoor Air Quality, Thermal Environment, Lighting and Acoustics. British Standard Institution; 2008.

[25] Subway environmental design handbook, VolumeI:Principles and Applications, Second Edition. Washington, D. C.: 1976.

[26] Wu L, Xia H, Wang X, Dong Q, Lin C, Liu X, et al. Indoor air quality and passenger thermal comfort in Beijing metro transfer stations. Transp Res Part D Transp Environ 2020;78:102217. https://doi.org/10.1016/j.trd.2019.102217.

[27] Code for design of metro (GB 50157-2013). Beijing: China Architecture \& Building Press; 2013.

[28] American Society of Heating Refrigerating and Air-Conditioning Engineers Inc. Enclosed Vehicular Facilities. 2019 ASHRAE Handb - Heating, Vent Air-Conditioning Appl (I-P Ed 2015:15.25.

[29] Standard I. ISO 7726 Ergonomics of the thermal environment - Instruments for measuring physical quantities. ISO Stand 1998;1998:1-56.

[30] Pan S, Liu Y, Xie L, Wang X, Yuan Y, Jia X. A thermal comfort field study on subway passengers during air-conditioning season in Beijing. Sustain Cities Soc 2020;61:102218. https://doi.org/10.1016/j.scs.2020.102218.

[31] Li G, Meng X, Zhang X, Zhang L, Du C, Li N, et al. An innovative ventilation system using piston wind for the thermal environment in Shanghai subway station. J Build Eng 2020;32:101276. https://doi.org/10.1016/j.jobe.2020.101276.

[32] Katavoutas G, Assimakopoulos MN, Asimakopoulos DN. On the determination of the thermal comfort conditions of a metropolitan city underground railway. Sci Total Environ 2016;566567:877-87. https://doi.org/10.1016/j.scitotenv.2016.05.047.

[33] Thompson JA, Maidment GG, Missenden JF. Modelling low-energy cooling strategies for underground railways. Appl Energy 2006;83:1152-62.

https://doi.org/10.1016/j.apenergy.2005.12.001.

[34] Clancy E. 2.3 Requirements for Good IAQ. Indoor Air Qual Vent - CIBSE Knowl Ser KS17 2011.

[35] Liu M, Zhu C, Zhang H, Zheng W, You S, Campana PE, et al. The environment and energy consumption of a subway tunnel by the influence of piston wind. Appl Energy 2019;246:1123. https://doi.org/10.1016/j.apenergy.2019.04.026.

[36] Kim M, Sankararao B, Kang O, Kim J, Yoo C. Monitoring and prediction of indoor air quality (IAQ) in subway or metro systems using season dependent models. Energy Build., vol. 46, 2012, p. 48-55. https://doi.org/10.1016/j.enbuild.2011.10.047.

[37] Wang Y, Li J, Li X. Subway simulation of CO 2 concentration during close mode operation. Sustain Cities Soc 2017;28:201-8. https://doi.org/10.1016/j.scs.2016.09.007. 
[38] Guan B, Zhang T, Liu X. Performance investigation of outdoor air supply and indoor environment related to energy consumption in two subway stations. Sustain Cities Soc 2018;41:513-24. https://doi.org/10.1016/j.scs.2018.06.009.

[39] Kim MJ, Liu H, Kim JT, Yoo CK. Evaluation of passenger health risk assessment of sustainable indoor air quality monitoring in metro systems based on a non-Gaussian dynamic sensor validation method. J Hazard Mater 2014;278:124-33. https://doi.org/10.1016/j.jhazmat.2014.05.098.

[40] Zhang Y, Li X. A study of fresh air control in subway stations. J Wind Eng Ind Aerodyn 2018;175:384-90. https://doi.org/10.1016/j.jweia.2018.02.008.

[41] Li Y, Zhang Q, Wang J, Yue C, Che L, Zhao J, et al. Field investigation on operation parameters and performance of air conditioning system in a subway station. Energy Explor Exploit 2019:014459871988122. https://doi.org/10.1177/0144598719881224.

[42] Hu SC, Lee JH. Influence of platform screen doors on energy consumption of the environment control system of a mass rapid transit system: Case study of the Taipei MRT system. Energy Convers Manag 2004;45:639-50. https://doi.org/10.1016/S0196-8904(03)00188-2.

[43] Juraeva M, Jin Ryu K, Jeong SH, Song DJ. Influence of mechanical ventilation-shaft connecting location on subway tunnel ventilation performance. J Wind Eng Ind Aerodyn 2013;119:114-20. https://doi.org/10.1016/j.jweia.2013.05.016.

[44] Liu M, Zhu C, Zhang H, Zheng W, You S, Campana PE, et al. The environment and energy consumption of a subway tunnel by the influence of piston wind. Appl Energy 2019;246:1123. https://doi.org/10.1016/j.apenergy.2019.04.026.

[45] Li G, You S. New multi-function integrated ventilation and air conditioning system for city rail transit. 2011 Int Conf Remote Sensing, Environ Transp Eng RSETE 2011 - Proc 2011. https://doi.org/10.1109/RSETE.2011.5965750.

[46] Pan S, Wang H, Pei F, Yang L, Zhang X. An Investigation on Energy Consumption of Air Conditioning System in Beijing Subway Stations. Energy Procedia 2017;142:2568-73. https://doi.org/10.1016/j.egypro.2017.12.093.

[47] Shih-Cheng Hu Y-CT and M-FH. Assessing the Potentials of Energy-Saving Strategies for an Underground Mass Rapid Transit System With Platform. Int J Archit Sci 2010;7:1-99.

[48] Yang L. Research on the Energy Use Characteristics and Energy Saving Strategies of Metro Stations. Tsinghua University, 2017.

[49] López González M, Galdo Vega M, Fernández Oro JM, Blanco Marigorta E. Numerical modeling of the piston effect in longitudinal ventilation systems for subway tunnels. Tunn Undergr Sp Technol 2014;40:22-37. https://doi.org/10.1016/j.tust.2013.09.008.

[50] Ke M-T, Cheng T-C, Wang W-P. Numerical simulation for optimizing the design of subway environmental control system. Build Environ 2002;37:1139-52.

[51] Pan S, Fan L, Liu J, Xie J, Sun Y, Cui N, et al. A review of the piston effect in subway stations. Adv Mech Eng 2013;2013. https://doi.org/10.1155/2013/950205.

[52] Li Z, Chen C, Pan S, Yan L, Li K. The effective use of the piston effect, natural cold sources, and energy saving in Beijing subways. Adv Mech Eng 2013;2013. https://doi.org/10.1155/2013/371785.

[53] Ma J, Zhang X, Li A, Deng B, Lv W, Guo Y, et al. Analyses of the improvement of subway station thermal environment in northern severe cold regions. Build Environ 2018;143:579-90. https://doi.org/10.1016/j.buildenv.2018.07.039. 
[54] Cao R, You S, Dong S. Experimental investigation and energy consumption analysis for subway side-platform in north cities. J Cent South Univ Technol 2009:235-8.

[55] Yang Z, Su X, Ma F, Yu L, Wang H. An innovative environmental control system of subway. J Wind Eng Ind Aerodyn 2015;147:120-31. https://doi.org/10.1016/j.jweia.2015.09.015.

[56] Zhang H, Cui T, Liu M, Zheng W, Zhu C, You S, et al. Energy performance investigation of an innovative environmental control system in subway station. Build Environ 2017;126:68-81. https://doi.org/10.1016/j.buildenv.2017.09.023.

[57] Zhang Y, Li X. Research on airflow and energy performance in PBD, PSD and PBD-PSDcombined environment control systems in subway. Sustain Cities Soc 2018;42:434-43. https://doi.org/10.1016/j.scs.2018.04.032.

[58] lv W, Li A, Ma J, Cui H, Zhang X, Zhang W, et al. Relative importance of certain factors affecting the thermal environment in subway stations based on field and orthogonal experiments. Sustain Cities Soc 2020;56:102107. https://doi.org/10.1016/j.scs.2020.102107.

[59] Zhang H, Zhu C, Zheng W, You S, Ye T, Xue P. Experimental and numerical investigation of braking energy on thermal environment of underground subway station in China's northern severe cold regions. Energy 2016;116:880-93. https://doi.org/10.1016/j.energy.2016.10.029.

[60] Yang L, Zhang Y, Xia J. Case study of train-induced airflow inside underground subway stations with simplified field test methods. Sustain Cities Soc 2018;37:275-87. https://doi.org/10.1016/j.scs.2017.11.003.

[61] Zhang X, Ma J, Li A, Lv W, Zhang W, Yang C, et al. Train-induced unsteady airflow effect analysis on a subway station using field experiments and numerical modelling. Energy Build 2018;174:228-38. https://doi.org/10.1016/j.enbuild.2018.06.014.

[62] Kong W, Zhu P, Xu W, Mei J, Wei W. Optimization of Operation Scheme for Subway Environmental Control System. Procedia Eng 2017;205:615-22. https://doi.org/10.1016/j.proeng.2017.10.414.

[63] Hu M, Liu M, You D, Zhang Y. Influence of train arrival characteristics on unorganized ventilation in underground subway station with platform screen doors. J Wind Eng Ind Aerodyn 2020;198:104089. https://doi.org/10.1016/j.jweia.2019.104089.

[64] Su Z, Li X. Sub-system energy model based on actual operation data for subway stations. Sustain Cities Soc 2020;52:101835. https://doi.org/10.1016/j.scs.2019.101835.

[65] Krasyuk AM. Calculation of Tunnel Ventilation in Shallow Subways. J Min Sci 2005;41:2617. https://doi.org/10.1007/s10913-005-0090-4.

[66] Quan J, Kim SH, Kim JH. A study on probabilistic social cost-benefit analysis to introduce high-efficiency motors into subway station ventilation. Energy Policy 2018;121:92-100. https://doi.org/10.1016/j.enpol.2018.06.007.

[67] Pan S, Pei F, Wei Y, Wang H, Liu J, Zhang X, et al. Design and experimental study of a novel air conditioning system using evaporative condenser at a subway station in Beijing, China. Sustain Cities Soc 2018;43:550-62. https://doi.org/10.1016/j.scs.2018.09.013.

[68] Chua KJ, Chou SK, Yang WM, Yan J. Achieving better energy-efficient air conditioning - A review of technologies and strategies. Appl Energy 2013;104:87-104. https://doi.org/10.1016/j.apenergy.2012.10.037.

[69] Afram A, Janabi-Sharifi F. Theory and applications of HVAC control systems - A review of model predictive control (MPC). Build Environ 2014;72:343-55. https://doi.org/10.1016/j.buildenv.2013.11.016. 
[70] Kim MJ, Braatz RD, Kim JT, Yoo CK. Indoor air quality control for improving passenger health in subway platforms using an outdoor air quality dependent ventilation system. Build Environ 2015;92:407-17. https://doi.org/10.1016/j.buildenv.2015.05.010.

[71] Loy-Benitez J, Li Q, Ifaei P, Nam K, Heo SK, Yoo C. A dynamic gain-scheduled ventilation control system for a subway station based on outdoor air quality conditions. Build Environ 2018;144:159-70. https://doi.org/10.1016/j.buildenv.2018.08.016.

[72] Lee S, Hwangbo S, Kim JT, Yoo CK. Gain scheduling based ventilation control with varying periodic indoor air quality (IAQ) dynamics for healthy IAQ and energy savings. Energy Build 2017;153:275-86. https://doi.org/10.1016/j.enbuild.2017.08.021.

[73] Li Q, Loy-Benitez J, Heo SK, Lee S, Liu H, Yoo CK. Flexible real-time ventilation design in a subway station accommodating the various outdoor PM 10 air quality from climate change variation. Build Environ 2019;153:77-90. https://doi.org/10.1016/j.buildenv.2019.02.029.

[74] Lee S, Kim MJ, Pyo SH, Kim JT, Yoo CK. Evaluation of an optimal ventilation IAQ control strategy using control performance assessment and energy demand. Energy Build 2015;98:134-43. https://doi.org/10.1016/j.enbuild.2014.08.040.

[75] Kim MJ, Braatz RD, Kim JT, Yoo CK. Economical control of indoor air quality in underground metro station using an iterative dynamic programming-based ventilation system. Indoor Built Environ 2016;25:949-61. https://doi.org/10.1177/1420326X15591640.

[76] Di Perna C, Carbonari A, Ansuini R, Casals M. Empirical approach for real-time estimation of air flow rates in a subway station. Tunn Undergr Sp Technol 2014;42:25-39. https://doi.org/10.1016/j.tust.2014.01.003.

[77] Casals M, Gangolells M, Forcada N, Macarulla M, Giretti A, Vaccarini M. SEAM4US: An intelligent energy management system for underground stations. Appl Energy 2016;166:150_ 64. https://doi.org/10.1016/j.apenergy.2016.01.029.

[78] Gangolells M, Casals M, Forcada N, MacArulla M, Giretti A. Energy performance assessment of an intelligent energy management system. Renew Sustain Energy Rev 2016;55:662-7. https://doi.org/10.1016/j.rser.2015.11.006.

[79] Gangolells M, Casals M, Forcada N, Macarulla M, Giretti A. Environmental impacts related to the commissioning and usage phase of an intelligent energy management system. Appl Energy 2015;138:216-23. https://doi.org/10.1016/j.apenergy.2014.10.070.

[80] Ansuini R, Larghetti R. Hybrid Modeling for Energy Saving in Subway Stations. 2012.

[81] Rigaut T, Nassiopoulos A, Bourquin F, Giroux P, Pény A. Model Predictive Control for Energy and Climate Management of a Subway Station Thermo-electrical Microgrid. Transp. Res. Procedia, vol. 14, Elsevier B.V.; 2016, p. 926-35. https://doi.org/10.1016/j.trpro.2016.05.072.

[82] Heo SK, Nam KJ, Loy-Benitez J, Li Q, Lee SC, Yoo CK. A deep reinforcement learning-based autonomous ventilation control system for smart indoor air quality management in a subway station. Energy Build 2019;202:109440. https://doi.org/10.1016/j.enbuild.2019.109440.

[83] Nam KJ, Heo SK, Li Q, Loy-Benitez J, Kim MJ, Park DS, et al. A proactive energy-efficient optimal ventilation system using artificial intelligent techniques under outdoor air quality conditions. Appl Energy 2020;266:114893. https://doi.org/10.1016/j.apenergy.2020.114893.

[84] Wang Y, Feng H, Xi X. Monitoring and autonomous control of Beijing Subway HVAC system for energy sustainability. Energy Sustain Dev 2017;39:1-12. https://doi.org/10.1016/j.esd.2016.12.004. 
[85] Zhang Y, Li X. Monitoring and analysis of subway tunnel thermal environment: A case study in Guangzhou, China. Sustain Cities Soc 2020;55:102057.

https://doi.org/10.1016/j.scs.2020.102057.

[86] Nurchis M, Valta M, Massimo V, Carbonari A. A Wireless System for Real-Time Environmental and Energy Monitoring of a Metro Station: Lessons Learnt from a Three-Year Research Project. 32nd Int. Symp. Autom. Robot. Constr., 2015. https://doi.org/10.22260/ISARC2015/0054.

[87] Revesz A, Chaer I, Thompson J, Mavroulidou M, Gunn M, Maidment G. Ground source heat pumps and their interactions with underground railway tunnels in an urban environment: A review. Appl Therm Eng 2016;93:147-54. https://doi.org/10.1016/j.applthermaleng.2015.09.011.

[88] Ampofo F, Maidment G, Missenden J. Underground railway environment in the UK Part 2: Investigation of heat load. Appl Therm Eng 2004;24:633-45. https://doi.org/10.1016/j.applthermaleng.2003.10.018.

[89] Ninikas K, Hytiris N, Emmanuel R, Aaen B, Younger PL. Heat recovery from air in underground transport tunnels. Renew Energy 2016;96:843-9. https://doi.org/10.1016/j.renene.2016.05.015.

[90] Davies G, Boot-Handford N, Curry D, Dennis W, Ajileye A, Revesz A, et al. Combining cooling of underground railways with heat recovery and reuse. Sustain Cities Soc 2019;45:543-52. https://doi.org/10.1016/j.scs.2018.11.045.

[91] Mortada A, Choudhary R, Soga K. Multi-dimensional simulation of underground subway spaces coupled with geoenergy systems. J Build Perform Simul 2018;11:517-37. https://doi.org/10.1080/19401493.2017.1407961.

[92] Ampofo F, Maidment GG, Missenden JF. Application of groundwater cooling scheme for London Underground network. Int J Refrig 2011;34:2042-9. https://doi.org/10.1016/j.ijrefrig.2011.05.016.

[93] Hytiris N, Ninikas K, Emmanuel R, Aaen B, Younger P. Heat Energy Recovery from Waste Water in the Glasgow Subway System. Procedia Eng., vol. 165, Elsevier Ltd; 2016, p. 394403. https://doi.org/10.1016/j.proeng.2016.11.715.

[94] Hytiris N, Ninikas K, Emmanuel R, Aaen B, Younger PL. A heat energy recovery system from tunnel waste water. Environ Geotech 2016;5:300-8. https://doi.org/10.1680/jenge.15.00087.

[95] Ninikas K, Hytiris N, Emmanuel R, Aaen B. Recovery and valorisation of energy fromwastewater using a water source heat pump at the glasgow subway: Potential for similar underground environments. Resources 2019;8. https://doi.org/10.3390/RESOURCES8040169.

[96] Thompson JA, Maidment GG, Missenden JF, Ampofo F. Geothermal cooling through enhancement of the natural heat sink effect - proof of concept. Exp Therm Fluid Sci 2007;31:551-8. https://doi.org/10.1016/j.expthermflusci.2006.06.002.

[97] Brandl H. Geothermal Geotechnics for Urban Undergrounds. Procedia Eng., vol. 165, Elsevier Ltd; 2016, p. 747-64. https://doi.org/10.1016/j.proeng.2016.11.773.

[98] Zhang G, Xia C, Yang Y, Sun M, Zou Y. Experimental study on the thermal performance of tunnel lining ground heat exchangers. Energy Build 2014;77:149-57. https://doi.org/10.1016/j.enbuild.2014.03.043.

[99] Zhang G, Guo Y, Zhou Y, Ye M, Chen R, Zhang H, et al. Experimental study on the thermal performance of tunnel lining GHE under groundwater flow. Appl Therm Eng 2016;106:784- 
95. https://doi.org/10.1016/j.applthermaleng.2016.06.041.

[100] Lai J, Wang X, Qiu J, Zhang G, Chen J, Xie Y, et al. A state-of-the-art review of sustainable energy based freeze proof technology for cold-region tunnels in China. Renew Sustain Energy Rev 2018;82:3554-69. https://doi.org/10.1016/j.rser.2017.10.104.

[101] Tong L, Songtao H, Shan L, Wang Y. Study on heat transfer performance of metro tunnel capillary heat exchanger. Sustain Cities Soc 2019;45:683-5. https://doi.org/10.1016/j.scs.2018.11.016.

[102] Tong Z, Cao T, Zang G, Hu S, Liu G, Wang Y. Performance analysis of capillary front-end heat exchanger for subway tunnel. Appl Therm Eng 2020;174:115360. https://doi.org/10.1016/j.applthermaleng.2020.115360.

[103] Ren M, Yuan Y, Cao X, Sun L, Jiang F. Numercial analysis on the thermal performance of capillary heat exchange system in metro running tunnel. Energy Built Environ 2020;1:207-14. https://doi.org/10.1016/j.enbenv.2020.01.003.

[104] Liu G, Li C, Hu S, Ji Y, Tong Z, Wang Y, et al. Study on heat transfer model of capillary exchanger in subway source heat pump system. Renew Energy 2020;150:1074-88. https://doi.org/10.1016/j.renene.2019.10.112.

[105] Ampofo F, Maidment G, Missenden J. Underground railway environment in the UK: Part 3: Methods of delivering cooling. Appl Therm Eng 2004;24:647-59. https://doi.org/10.1016/j.applthermaleng.2003.10.019.

[106] Kim JY, Kim KY. Effects of vent shaft location on the ventilation performance in a subway tunnel. J Wind Eng Ind Aerodyn 2009;97:174-9. https://doi.org/10.1016/j.jweia.2009.06.002.

[107] Yin H, Yang C, Yi L, Yu J, Wu Y, Deng Y, et al. Ventilation and air conditioning system of deep-buried subway station in sub-tropical climates: Energy-saving strategies. Appl Therm Eng 2020;178:115555. https://doi.org/10.1016/j.applthermaleng.2020.115555.

[108] Oropeza-perez I, Østergaard PA. Active and passive cooling methods for dwellings : A review. Renew Sustain Energy Rev 2018;82:531-44. https://doi.org/10.1016/j.rser.2017.09.059.

[109] Chen Q. Ventilation performance prediction for buildings: A method overview and recent applications. Build Environ 2009;44:848-58. https://doi.org/10.1016/j.buildenv.2008.05.025. 